\title{
1 Predicting avian herbivore responses to changing food availability and competition
}

2 Kevin A. Wood ${ }^{1 *}$, Richard A. Stillman ${ }^{2}$, Julia L. Newth ${ }^{1,3}$, Rascha J.M. Nuijten ${ }^{4}$, Geoff M.

3 Hilton $^{1}$, Bart A. Nolet ${ }^{4,5}$ \& Eileen C. Rees ${ }^{1}$

$4 \quad{ }^{1}$ Wildfowl \& Wetlands Trust, Slimbridge, Gloucestershire, GL2 7BT, United Kingdom.

$5 \quad{ }^{2}$ Department of Life \& Environmental Sciences, Faculty of Science \& Technology,

6 Bournemouth University, BH12 5BB, United Kingdom.

$7 \quad{ }^{3}$ Centre for Ecology and Conservation / Environment and Sustainability Institute, College of

8 Life and Environmental Sciences, University of Exeter, TR10 9EZ, United Kingdom.

$9{ }^{4}$ Department of Animal Ecology, Netherlands Institute of Ecology, Droevendaalsesteeg 10, 6700 AB, Wageningen, The Netherlands.

$11{ }^{5}$ Department of Theoretical and Computational Ecology, Institute for Biodiversity and 12 Ecosystem Dynamics, University of Amsterdam, Science Park 904, 1098 XH Amsterdam, 13 The Netherlands.

14 *Corresponding author: kevin.wood@wwt.org.uk

Running title: Predicting avian herbivore responses

Abstract

Many species of large herbivore rely on agricultural land for their feeding habitats, but available food resources are highly variable in space and time. The conservation and management of farmland-dependent herbivores would therefore benefit from predictions about how species will respond to changes in their environment. We developed an individualbased model (IBM) to provide such predictions for three overwintering avian herbivore 
species that feed on agricultural land: Bewick's swans (Cygnus columbianus bewickii), whooper swans (Cygnus cygnus), and mute swans (Cygnus olor). Our validated model predicted how potential future changes in food availability and competition would affect (i) the proportion of the current swan population that could be supported, (ii) the proportion of swans that successfully departed on migration at the end of winter, (iii) swan daily foraging effort, and (iv) late winter crop biomasses. Regardless of competitor numbers or food availability, all individuals were predicted to avoid starvation and depart successfully. Individual swans offset higher competition and reduced food availability by increasing the proportion of daylight spent foraging. Our simulations indicate that swans have considerable capacity to buffer against losses of food resources and increased competition by increasing their foraging effort, but this may result in additional grazing damage to agricultural crops. Our findings suggest that the recent c. $40 \%$ decline in Bewick's Swan numbers was unlikely to be linked to changes in winter food resources or competition.

37 Key words: Agent-based simulation; Agricultural landscape; Ecological forecasting; Food resources; Global environmental change; Land use change 


\section{Introduction}

Since the mid-twentieth century, agricultural land has supported increasingly large numbers of avian herbivores (Newton, 2017). High-energy crops can provide important food resources for herbivores, especially during winter when the availability of natural vegetation is low (Clausen et al., 2018a), but the types and spatial extent of crops available to herbivores vary both spatially and temporally due to environmental conditions as well as farming practices and economic incentives. Such food resources may be lost permanently to herbivores when fields are converted from agriculture to other uses, including housing and infrastructure (Döös, 2002). Understanding how avian herbivores respond to changes in the availability of food resources, which may be caused by reduced availability of key crop types or increased competition with other herbivores, is critical not just for the conservation of these species, but also for addressing the damage to crops that such birds can cause (e.g. Madsen, 2015; Petkov et al., 2017).

In northwest Europe, avian herbivore species that use arable land include Bewick's swans (Cygnus columbianus bewickii), mute swans (Cygnus olor), and whooper swans (Cygnus cygnus) (Rees et al., 1997; Wood et al., 2019c). During winter these species feed on the postharvest remains of energy-rich crops such as maize (Zea mays), sugar beet (Beta vulgaris), and potatoes (Solanum tuberosum), actively-growing autumn-sown crops such as wheat (Triticum aestivum) and oilseed rape (Brassica napus), and in some areas pasture grasses (e.g. Lolium perenne). Following their arrival on the winter grounds, swans need to regain energy lost during earlier movements, and also to gain and maintain adequate energy reserves to allow them to survive winter and initiate subsequent migratory flights to their breeding grounds and reproduce successfully (Bêty et al., 2003; Drent et al., 2006). Such energy demands are particularly acute for long-distance migratory species such as Bewick's and whooper swans (Rees, 2006). Indeed, where avian herbivores experience poor conditions on 
their winter grounds, subsequent survival probability and breeding success may be reduced (Inger et al., 2010; Harrison et al., 2011). Hence, such herbivores are known to track the most profitable food resources within a landscape, switching feeding areas in order to achieve the greatest net rate of energy gain (Nolet et al., 2002; Wood et al., 2019b). However, the quantity of different crops cultivated in an area can be highly sensitive to changes in agricultural policies and economic conditions, including the availability of subsidies to grow crops such as sugar beet and maize (Poonyth et al., 2000). Seasonal weather conditions also influence crop growth rates and abundance (Cantelaube and Terres, 2005). Consequently, the food supply available to swans fluctuates over time (Wood et al., 2019c).

As the three swan species exploit the same food resources within the same habitats, the potential for inter- and intra-specific competition between individuals exists, with the smaller Bewick's swans held to be the least dominant in such interactions, while whooper swans also appear to be dominant over mute swans (Black and Rees, 1984; Butkauskas et al., 2012). Individuals suffer reduced intake rates at high competitor densities because of interference and avoidance behaviour (Gyimesi et al., 2010). A study of interference competition among Bewick's swans by Gyimesi et al. (2010) concluded that at densities of $>500$ individuals $\mathrm{ha}^{-1}$, the intake rate of an average swan was only c. $25 \%$ of the interference-free intake rate (i.e. the intake rate at a density of 1 individual $\mathrm{ha}^{-1}$ ). Numbers of both whooper and mute swans have increased in recent decades (Wood et al., 2019a), whilst Bewick's swans declined by c.40\% in number between 1995-2010 and have been classified as Endangered in Europe (Beekman et al., 2019), and so the foraging competition experienced by individual swans has also changed over time. Indeed, it has been suggested that competition at key feeding sites could have contributed to the decline of the Bewick's swan (Nagy et al., 2012), although this hypothesis has not yet been tested. 
To inform swan conservation and management, research is needed to understand how sensitive swans are to potential changes in arable food resources and competition. Behavioural adjustments, such as increasing the time spent foraging or moving to an alternative feeding area nearby, may allow birds to buffer against some reductions in food availability or increased competition (e.g. Pot et al., 2019), but the limits of such mechanisms are not well understood currently.

In this study we developed an individual-based model (IBM) to examine the sensitivity of swans to changes in (i) food availability, (ii) interspecific and intraspecific competition. IBMs have been developed to make predictions about the behaviour, movement and state of individual animals within a population (Grimm and Railsback, 2005). To make such predictions, IBMs incorporate an array of data on individual animal agents of different species and age classes, including aspects of life history, behaviour, and physiology, as well as the abundance and characteristics of their food resources within a landscape. Given this flexibility, IBMs have been shown to be powerful tools for informing the conservation of populations affected by environmental change (Stillman et al., 2015a). Our hypotheses were, firstly, that swans would be able to buffer against some losses of food by increasing their foraging effort, but second that the capacity of any such buffering would be exceeded by higher competitor densities.

\section{Methods}

\subsection{Study system}

The Ouse Washes $\left(52^{\circ} 31^{\prime} \mathrm{N}, 0^{\circ} 16^{\prime} \mathrm{E}\right)$ are seasonally-flooded grazing pastures in eastern England, which have been designated as a Special Protection Area (SPA) under the European 
Union Birds Directive, a Ramsar Site under the Convention on Wetlands, and a Site of Special Scientific Interest (SSSI) under the UK's Wildlife and Countryside Act, in recognition of their importance for swans and other wildlife. The Ouse Washes support up to $38 \%$ of the winter population of Bewick's Swans in northwest Europe, up to $21 \%$ of the winter numbers of the Icelandic-breeding whooper swan population, and up to $4 \%$ of the Mute Swan population resident in Great Britain (Ward et al., 2002; Hall et al., 2016; Wood et al., 2019c). Swan numbers recorded on the Ouse Washes and surrounding landscape have fluctuated markedly over time; between winters 1965/66 and 2018/19 the total numbers of all three species rose 12 -fold from 1,051 to 12,621 individuals, with the latter total comprising 1,140 Bewick’s, 304 mute, and 11,177 whooper swans (Frost et al., 2020). Bewick's and whooper swans typically arrive in October/November and depart during February/March, with mute swans also present in the fields between January-March (Wood et al., 2019b). The agricultural land surrounding the Ouse Washes comprises a mosaic of arable fields intersected by drainage ditches, and represents a key feeding area for swans (Owen and Cadbury 1975; Wood et al., 2019c). The three swan species feed on a range of crops, including the post-harvest remains of spring-sown sugar beet, potatoes, and maize, as well as autumn- or winter-sown crops such as wheat and oilseed rape (Rees et al., 1997; Wood et al., 2019b). Fields are typically free of frost and ice for much of the winter (Appendix A).

Our study area represented within the model comprised the main $3.5 \mathrm{~km}^{2}$ wetland roost site, together with $15.4 \mathrm{~km}^{2}$ of farmland at Southery Fen $\left(52^{\circ} 30^{\prime} \mathrm{N}, 0^{\circ} 23^{\prime} \mathrm{E}\right)$, a major feeding area approximately $7.5 \mathrm{~km}$ south-east of the main roost site. This feeding area was selected as it had been consistently used by all three swan species over successive winters and contained all of the major crop types used by the swans. 


\subsection{Model description}

To provide a comprehensive description of our model, we used the ODD (Overview, Design concepts, Details; Grimm et al., 2020) protocol, adapted from the ODD protocol of the original MORPH model developed by Stillman (2008).

\subsubsection{Purpose and patterns}

The purpose of our model was to predict the changes in swans' (Cygnus spp.) overwinter survival and behaviour in response to changes in the availability of their food resources and the levels of competition experienced by individuals in the agricultural landscapes that comprise their winter grounds in northwest Europe. As our predictions related to potential future conditions that could be experienced by the model birds and their real-world counterparts, our model made anticipatory predictions sensu Maris et al. (2018).

The patterns used to evaluate whether our model made sufficiently realistic predictions to meet its stated purpose were: (i) the proportion of the model swans that could be supported by the study area within the model, (ii) the proportion of swans that successfully emigrated in late winter, (iii) the total amount of time spent by swans on foraging behaviour each day, and (iv) the biomasses of each crop type in late winter. Model predictions were considered to have achieved a sufficient match where those mean predictions were equal to the observed values, or at least within the $95 \%$ confidence intervals of the observed values. Models that only reproduced accurate patterns for some but not all of these four tests were considered inadequate. Data on each of these four patterns were available from fieldwork undertaken in the study area (Appendix B). 
159 Our model defined the following entities: the global environment, patches, resources, 160 components, and swans (Table 1).

\subsubsection{Global}

The global environment of our model was comprised of three state variables: time, day, and daylight. Within the model, time progressed in discrete time steps, each of which represented one hour of real-world time. The one hour time step was selected as this was considered a biologically relevant period of time over which swans make behavioural decisions such as where to feed, and accords with the time step duration used previously in MORPH IBMs of swans (e.g. Wood et al., 2014; Nolet et al., 2016). One day was equivalent to 24 hourly time steps. The model covered a period of 151 days from 1st November to 31st March (a total of 3624 hourly time steps), based on the period in which the study area was used by overwintering swans (Wood et al., 2019c). As swans are typically diurnally active (Rees, 2006), our model incorporated the daily variation in the times of sunrise and sunset in the study site; the model featured a binary daylight variable, which during hours of daylight was set to a value of 1 , whilst outside of daylight hours the value of this variable was set to 0 . These values were based on data on real-world daylight hours for our study site (USNO, 2018).

\subsubsection{Patches}

Our spatially-explicit model was comprised of discrete patches that represented the study area. In total, the model world was comprised of 61 discrete patches, with one patch 
representing the swans' wetland roost and 60 patches each representing one of the arable

182 fields available to the birds as potential foraging habitat (Table 2). The total area of all of the model patches represented a real-world area of $18.9 \mathrm{~km}^{2}$. The roost site was $3,499,732 \mathrm{~m}^{2}$, while the sizes of the field patches ranged between 4,078-721,403 $\mathrm{m}^{2}$ (mean $\pm \mathrm{SD}=134,954$ $\left.\pm 129,476 \mathrm{~m}^{2}\right)$.

\subsubsection{Resources}

Each of the field patches contained one or more crop type, which represented the food resources used by the swans. Crops were assigned to field patches based on the type of crop that was recorded in the corresponding real-world field during monthly surveys in winter 2016/17. The crop types were: wheat, oilseed rape, sugar beet, potatoes, and maize (Table 2). Each field patch contained an initial biomass density $\left(\mathrm{g} \mathrm{DM} \mathrm{m}^{-2}\right)$ for each crop type, which fluctuated subsequently over the course of the simulation according to a submodel for rates of growth or senescence (section 2.2.7.1), as well as depletion by foraging swans within the model. Each month between November 2016 and March 2017, sampling was conducted in each field within the study area to determine the dry matter (hereafter 'DM') biomass density of each crop in that field. Sampling was conducted in areas of the field not used by the birds (based on the absence of cropped vegetation, swan faeces or feathers, which are indicative of the presence of foraging swans), so that we could quantify crop dynamics independent of depletion by the swans. Destructive sampling of wheat and oilseed rape in each field was not possible as these were actively-growing, economically valuable crops, and so a relationship between biomass and sward height was determined and used to estimate biomass from sward height (see below). Sward height for wheat and oilseed rape was measured in each month in each field ( $n=10$ measurements per field per month) as described in Wood et al. (2019b). To 
facilitate the calibration of sward height against biomass, in one wheat field and one oilseed rape field that were representative of the study area in size and farming practices, we harvested all aboveground tissues using a $0.00785 \mathrm{~m}^{2}$ core sampler $(n=20$ per field per month). To determine DM biomass, each sample was dried to constant mass at $60{ }^{\circ} \mathrm{C}$ using a Genlab PRO-100 General Purpose Oven (Genlab, USA) and then weighed ( $\pm 0.1 \mathrm{~g})$ using a Pesola PTS3000 digital balance (Pesola Präzisionswaagen AG, Switzerland). These samples also enabled the determination of energy content (see below). We estimated post-harvest maize, sugar beet, and potato crops biomasses per field in each month by excavating all crop remains within $1 \mathrm{~m}^{2}$ plots ( $n=10$ per field per month), as per Wood et al. (2019b). Non-crop material was removed from each sample, which was then dried to constant mass as described above, before DM biomass was measured.

\subsubsection{Components}

Only one component was defined in our model: energy. Each crop type contained a specified quantity of energy $\left(\mathrm{kJ} \mathrm{g}^{-1}\right)$ that could be consumed and assimilated by swans during foraging. The energy content value was crop-specific and was fixed for the duration of the simulation calorimetry using a Parr 1108 Oxygen Combustion Bomb (Parr Instrument Company, (Table 2). Parameter values were determined from samples collected from the study area. The gross energy content $\left(\mathrm{kJ} \mathrm{g}^{-1} \mathrm{DM}\right)$ of each food resources was determined with bomb Illinois, USA), based on $500 \pm 1 \mathrm{mg}$ DM samples ( $n=5$ per crop type per month) collected and dried as described above. As Wood et al. (2019b) found no temporal trends in the gross energy contents either cereal or root crops over winter, we used fixed values for the gross energy content of each crop type in our model. 
230 The agents in our model represented swans, each of which belonged to one of the three 231 species (Bewick's swan, mute swan, or whooper swan) and one of the two age classes (adult or cygnets), and hence there were six different types of agent. The species and age class of a swan were fixed and so did not change during the simulation. We modelled 116 Bewick's Swans (101 adults and 15 cygnets), 20 mute swans (15 adults and 5 cygnets), and 271 whooper swans (216 adults and 52 cygnets), based on the maximum numbers observed during the monthly crop data collection visits to the study area (Table 3). Each individual swan had a state variable representing its individual usable energy store $(\mathrm{kJ})$, which could be added to through the intake of energy whilst foraging, or depleted by the expenditure of energy on behavioural activities: resting, foraging, and flying (section 2.2.7.4). Each type of agent could gain energy by foraging on a given food resource according to a functional response equation that described intake rate $\left(\mathrm{g} \mathrm{DM} \mathrm{s}^{-1}\right)$ as a function of crop biomass density $\left(\mathrm{g} \mathrm{DM} \mathrm{m}^{-2}\right)$, the energy content of the crop type $\left(\mathrm{kJ} \mathrm{g}^{-1} \mathrm{DM}\right)$, and the proportional assimilation efficiency of the forager type for a given crop type (see below).

\subsubsection{Process overview and scheduling}

Within the model, time progressed according to discrete one-hour time steps, which spanned 151 days from 1 st November to 31 st March, based on the period of use by overwintering swans (Wood et al., 2019c). The following processes occurred on each time step: (i) update of crop biomass values in each patch, (ii) immigration of swans, if required; (iii) swan decision making, and (iv) swan energy gain and expenditure (Figure 1). 
251 On each time step, the model carried out these steps according to the relevant submodels

252 (section 2.2.7). The first process was to update the biomass density of each resource in each patch, according to the rate of change independent of depletion by swans (section 2.2.7.1). The model then created any swans that were due to immigrate into the study area on that time step, to simulate the arrival of swans into the study area. Individual swans entered the model according to species-specific arrival dates (section 2.2.7.2; Table 3).

Each swan that was present within the model then, in turn, made a behavioural decision, for example to select a patch and either exploit a given resource or rest (section 2.2.7.3; Figure 2). The model then enacted that decision for that individual swan, with the energy store of that individual being updated to reflect the energy gains from foraging and losses from behaviours (crop biomass density was also updated to reflect any depletion due to consumed resources). The decision of each swan was enacted before the next swan was allowed to make a decision, i.e. asynchronous scheduling was used. Asynchronous scheduling was required as preliminary testing of the original MORPH model found that the alternative strategy of synchronous scheduling, in which all swans made and enacted their decisions simultaneously, produced unrealistic patterns of behaviour (Stillman, 2008). Stillman (2008) found that if one patch contained a marginally higher resource biomass density than others at the start of a time step, then all foragers would congregate on that patch, even if progressive depletion by the foragers resulted in that patch containing a much lower resource biomass density than other patches by the end of a time step. Our approach of asynchronous scheduling avoided such problems because after the first swan within a time step had been processed, swans processed subsequently within that time step would select a patch and diet whilst accounting for the 273 depletion and interference associated with the cumulative decisions and behaviours of all swans that had already been processed. 
The order in which the model processed the individual swans was determined by their dominance rank. As part of our strategy to model interspecific competition we used a dominance hierarchy for foraging interactions that reflected that whooper swans are typically dominant over both mute and Bewick's swans, whilst mute swans are dominant over Bewick’s swans (Black and Rees, 1984; Butkauskas et al., 2012). Within each species, adults and juveniles were assigned the same dominance rank, as juvenile swans typically associate with their parents during their first winter and are thus afforded their parent's protection during aggressive encounters (Scott, 1980). Moreover, previous research has demonstrated that adult and juvenile swans among flocks have equal foraging success where food is dispersed (Milinski et al., 1995), as is the case with crops which are cultivated across entire fields. On each time step the model processed (i.e. allowed them to make and enact their movement and foraging decisions) whooper swans first, mute swans second, and Bewick's swans third, with the order of individuals within each species chosen at random.

Once the species-specific date of first possible departure had been reached, individuals swans could leave the model permanently only if they currently met their target energy store; otherwise, the individual remained within the model until the next time step (Figure 2). On each hourly time step during daylight, individuals used the maximisation of net energy gain as a decision rule to determine which patch it should move to and which resource type it should consume, as previous research has found that real swans select feeding habitat so as to maximise their net rates of energy gain (Nolet and Klaassen, 2009; Wood et al., 2019b).

Once these processes have been completed, the number of time steps elapsed is increased by one and the model proceeds to the next time step, until the $3624^{\text {th }}$ time step has elapsed, at which point the simulation ends. 


\subsubsection{Basic principles}

301

The decision rule that governs the behaviour of all individual swans within our model was based on the principle of individuals as fitness maximizing agents (Grafen, 1999). In our model we used the net rate of energy gain as a proxy for fitness maximization in foraging swans, as previous research has shown that net energy gain performs well as an explanatory framework for behavioural decision-making among herbivores, including selection of feeding patches and diet choice (Sih and Christensen, 2001; Wood et al., 2019b). Such fitnessmaximizing models are application of game theory and are based on the ideal free distribution (Fretwell and Lucas, 1970), with the assumption that individuals move to exploit patches and resources which provide the highest net energy gain (Sutherland, 2006). The decision rules of the model are based on adaptive behaviour, hence the principle that an individual should act so as to maximize its perceive fitness is not expected to vary even as the environment changes (Stillman et al., 2015a). As such, models based on fitness-maximizing decision rules are considered to be more likely to maintain their predictive power as environmental conditions change when compared with the empirical relationships of traditional correlative methods (Sutherland, 2006; Stillman et al., 2015a). Such fitnessmaximizing models are therefore well-suited to making predictions under future environmental conditions (Wood et al., 2018b).

\subsubsection{Emergence}

The fitness maximising decision rules that govern the behaviour of the swans allow the following phenomena to emerge from our model simulations: (i) swan distribution, (ii) 
selection of diet (i.e. crop type) by swans, (iii) the proportion of time spent foraging by swans, (iv) swan component (i.e. energy) store size, and (v) swan mortality and emigration from the model.

\subsubsection{Adaptation}

The adaptive behaviours associated with the swans were their decisions regarding patch location and their selection of diet (i.e. crop type). Each of the potential decisions that a swan could make (i.e. which patch and diet to select, or whether to emigrate) had an associated value that represented the perceived fitness of that decision. Swans behaved according to the fitness maximising decision rule, such that swans made the behavioural decision that yielded the maximum fitness value for that time step; for example, during daylight a swan would move to the patch and consume the diet that in combination gave the maximum possible fitness value (when compared with all other patch and diet combinations), or else emigrate if that decision had a higher fitness measure and the departure date had been reached (see section 2.2.4.3).

\subsubsection{Objectives}

The objective of each individual swan, as encoded by the decision rule, was to maximum their fitness value for that time step (see section 2.2.4.3). During daylight time steps swans would move to the patch and consume the diet that, together in combination, gave the maximum possible fitness value (when compared with all other patch and diet combinations. Swans were only permitted to forage during daylight, as is typically observed for their realworld counterparts (Rees, 2006). On time steps with no daylight, swans instead received the 
maximum possible fitness value for being present on the roost patch; this simulated the behaviour observed for the real-world swans, which return to their wetland roost site each

347 night at dusk and remain there until dawn (Rees, 2006; Wood et al., 2019c). However, where swans had met their target energy store and the departure date had been reached for that

349 forager type, the maximum fitness value would be achieved by emigration; hence individuals would emigrate permanently from the model on the first time step in which these conditions were met.

\subsubsection{Learning}

354 During a simulation the swans in our model did not alter the adaptive, fitness maximizing 355 decision rule that governed their behaviour (see section 2.2.4.4).

\subsubsection{Prediction}

358 Swans did not predict future environmental conditions within the model, for example the 359 biomass densities of crop types within patches in future time steps. Instead, our swans reacted to the environmental conditions of the current time step according to their fitness maximizing decision rules (see section 2.2.4.4). To make predictions regarding swan responses to potential future levels of food resources or competition, we ran separate discrete simulations of our model (section 2.5). 
Swans were assumed to know their own dominance relative to other swans, as well as their

367

368

369 own physiological state, for example, their current energy store, on each time step. Our model swans were also assumed to have a perfect knowledge of the resources and other foragers contained in each patch in each time step. We believe that perfect knowledge of foraging conditions within our study area was a reasonable assumption for highly mobile foragers such as swans, given that previous research has suggested that avian herbivores use visual cues to assess the relative profitability of food resources (Owen, 1976). In our study system such cues could be gained during their daily commuting flights between their roost and feeding area. Such an inference is supported by previous research that has shown that swans do indeed select the most profitable food resources within a landscape (e.g. Wood et al., 2013; Nolet and Klaassen, 2009; Wood et al., 2019b).

\subsubsection{Interaction}

Individual swans interacted within patches through two mechanisms, which simulated the effects of competition: (i) the consumption of a shared resource (depletion competition), and (ii) reduction in intake rates when sharing a patch with other swans (interference competition) (as described in section 2.2.2.2). The presence of other swans within the model also affected the order in which individual swans made their behavioural decisions, based on their dominance hierarchy (section 2.2.2.2).

\subsubsection{Stochasticity}

Within each forager type, the order in which swans made their behavioural decisions was randomised on each time step. Aside from this, our model was deterministic, and we 
confirmed through initial model exploration that model predictions did not vary between model runs with the same parameter values. The effects of variation in parameter values on our predictions was assessed through a sensitivity analysis.

\subsubsection{Collectives}

As swan densities on each patch affected the patch selection and intake rates of swans, the density of swans in each patch during each time step represented the key collective in our model. The dominance rank specific to each forager type specified the dominance hierarchy among swans, which determined the order in which individuals made their behavioural decisions on each time step. One individual swan within the model represented one realworld individual, i.e. we did not use 'super-individuals' sensu Scheffer et al. (1995).

\subsubsection{Observation}

All of the state variables featured in our model could be displayed and saved during each time step. The Graphical User Interface (GUI) associated with our model displayed the model world, including the distribution of patches and swans on those patches, as well as information on the state variables.

\subsubsection{Initialization}

At the beginning of each simulation the global, patch, and forager constants in our model were initialized, and all patches and their initial resources were created. The initial component stores for each individual swan were initialized upon the immigration of that 
individual into the model. The model parameters were specified within a dedicated parameter

412 file, and took the form of either: (i) values constant over all time steps (for example, the swans' assimilation efficiency for a given crop type), (ii) values for each time step (which could be read in from an external file, for example the daylight parameter), or (iii) calculated by a submodel during each time step from state variables defined earlier in the parameter file (for example, swan intake rates for specific crop types in specific patches).

\subsubsection{Input data}

In addition to the parameter values specified in the model's parameter file, our model also required a separate input file to be read in, which specified whether the daylight parameter (see section 2.2.2.1) should be set to 1 (i.e. daylight) or 0 (i.e. not daylight) on each time step. The information required for all other parameter values was contained within the parameter file.

\subsubsection{Submodels}

There were a total of four submodels used within our model, which were associated with (i) changes in resource biomass densities, (ii) the immigration of swans to the model, (iii) swan decision making and behaviour, and (iv) swan energy gain and expenditure.

2.2.7.1 Changes in resource biomass densities. At the start of each time step, (with the exception of the first time step, on which the initial biomass densities were set), the change in the biomass density of each resource (crop type) in each patches due to natural growth and 
senescence (i.e. independent of depletion by swans) was calculated by a submodel, informed

434

435

436

437

by our field data (section 2.2.2.3). According to our submodel, the rate of change in the biomass density of each crop type independent of depletion by swans $\left(B_{c} ; \pm \mathrm{g} \mathrm{DM} \mathrm{m}^{-2} \mathrm{hr}^{-1}\right)$ was modelled as:

$B_{c}=\left(B_{m}-B_{m+1}\right) / T$

where $B_{m}$ and $B_{m+1}$ were the crop-specific mean biomass values for a given month and the subsequent month, respectively, and $T$ was the number of hourly time-steps between the sampling dates in those two months.

In addition to the changes in resource biomass density that were independent of depletion by swans, our model also accounted for the quantity of each resource in each patch that was consumed by foraging swans during each time step. Depletion by swans was incorporated by reducing the quantity of a resource within each patch by the amount consumed by the swans. This step was carried out immediately after the resource biomass had been consumed by each swan in turn (i.e. before the model moved on to simulate the decisions and behaviour of the next swan).

\subsubsection{Swan immigration.}

Individuals entered the model according to species-specific arrival dates, based on field observations of when the different swan species typically arrive in the study area (Table 3).

The submodel created the required number of swans on the first time step once the specified date had been reached. 
456 On each time step all swans currently present within the model made decisions regarding

457 which patch to select and which resource to consume within that patch, if any. These decisions were performed by a submodel according to the fitness maximizing objectives that governed the behaviour of all swans (section 2.2.4.4). Swans had knowledge of the energy gain (the proxy measure of fitness) that they would receive from foraging on each resource type in each patch within the model, as well as the energetic costs of moving to and exploiting those patches. These net energy gain calculations also accounted for the presence of other swans in each patch. Hence swans could calculate the potential net energy gain of all possible decisions. During daylight a swan would move to the patch and consume the diet that in combination gave the maximum possible net energy gain (which could include remaining on their current patch, consuming their current diet), or else emigrate if that decision had a higher fitness measure and the departure date had been reached (see section 2.2.4.3). At the start of the first time step after dusk, the swans flew to the roost patch, where they remained until dawn, as per the behaviour of the real swans (Rees, 2006). If a swan moved to either a feeding or roost patch, then a subsequent submodel was used to determine swan energy gain and expenditure (section 2.2.7.4), based on that decision.

\subsubsection{Swan energy gain and expenditure.}

474 The energy store of each individual was updated by a submodel on each time step, based on

475 the behavioural decisions made by the individual during that time step. Individuals gained energy by feeding on resources within the field patches, and expended it on foraging, resting, and flying behaviours. 
478 Upon first arrival (i.e. immigration to the model as per section 2.2.7.2), each individual swan was assigned an energy store, which represented a quantity of energy available to be spent on behavioural activities such as foraging. This energy store value was based on a body mass that was specific to its species and age class. Each individual also had a target energy store value that they attempted to reach on every time step; this target represented the values that the bird aimed to achieve before departure from the winter area, which was calculated based on the mean body mass values of birds caught in late winter (Table 3). Arrival body masses of the two migratory swan species (Bewick's and whoopers) were estimated from the data on adult and cygnet Bewick's swans reported by Evans and Kear (1978). For each sex and ageclass we first calculated the mean body mass measured in the half-month of arrival as a proportion of the mean body mass measured in the final half-month before departure. We then took a mean of these male and female Bewick's swan proportions for each age-class, which gave arrival mass values that were 0.854 and 0.813 of adult and cygnet final mass values, respectively. These age-class specific mean proportions were multiplied by the target body mass values for the migratory Bewick's and whooper swans (Table 3). In contrast, our focal mute swans undertake only local movements, and arrival body mass was set at $1.0 \mathrm{~kg}$ lower than the target departure mass based on the seasonal mass fluctuations reported by Bacon and Coleman (1986). The energy store $(E$, in $\mathrm{kJ})$ of each individual for a given time step $(t)$ as:

$E_{t}=\left(M_{t}-M_{\text {Lean }}\right) * E_{\text {Avian }}$

where $M_{t}$ and $M_{\text {Lean }}$ were the body mass on time step $t$ and lean body mass of that species and age class (Kear, 2005; Rees, 2006), respectively, and $E_{\text {Avian }}$ was the energy content of avian energy storage tissues (27.5 $\mathrm{kJ} \mathrm{g}^{-1}$; Madsen and Klaassen, 2006; Table 3). All individuals were assigned proportional efficiencies for catabolism and anabolism of 1.0 and 0.8 , respectively (Blaxter, 1989). 
Whilst individuals' current energy store remained lower than their target energy store, the birds foraged to attempt to meet their target. Once an individual reached the target energy store it could not gain or store additional energy, and so rested until its current energy store once again fell below the target. Individuals starved if their energy store was reduced to $\leq 0$ and were removed from the model. During short foraging flights swans have a velocity of approximately $12.8 \mathrm{~m} \mathrm{~s}^{-1}$ (Nolet et al., 2002; van Gils and Tijsen 2007) and hence could cover our study area in considerably less than the hourly time step of our model; therefore, foragers were allowed to move between patches within a single time step. To account for the energetic costs of daily return flights, we estimated the total daily flight cost for each forager type as the costs of flight as a multiple of BMR (Table 3) multiplied by the total daily time spent in flight. This flight time (586s) was calculated as twice the distance between the roost and feeding areas (i.e. $2 \times 7.5 \mathrm{~km}$ ), divided by flight speed. This expenditure was modelled as an additional cost incurred by all foraging birds, spread over diurnal time steps (Table 3).

The rates at which each forager type consumed given types of food resource were modelled as Type II functional response curves, which describe food intake as increasing with food density but with an decelerating increase up to an asymptote (Holling, 1959). Previous research has shown that the intake rates of avian herbivores feeding on actively-growing, leafy vegetation or crop remains typically conform to a Type II functional response (e.g. Nolet et al., 2002; Durant et al., 2003; Van Gils et al., 2007; Wood et al., 2013).

We used a Type II functional response, to model swan intake rates for swans foraging on wheat and oilseed rape, using the formulation reported by Baveco et al. (2011). This functional response was based on bite size ( $S$; grams Dry Matter), as measured experimentally by van Gils et al. (2007) for adult Bewick's swans foraging on pasture grass, and handling time ( $T_{h}$; seconds), following the approach of Spalinger and Hobbs (1992): 
$528 T_{h}=\left(T_{c 0}+c \cdot H\right)+1 / R_{\max } \cdot S$,

529 where $b_{1}\left(0.138 \mathrm{~g} \mathrm{DM} \mathrm{m}^{-1}\right.$; van Gils et al., 2007) and $b_{2}\left(0.0 \mathrm{~g} \mathrm{DM} \mathrm{m}^{-1}\right.$; Baveco et al., 2011)

530 were regression coefficients that described the relationship between bite size and vegetation

531 height, $H$ was the vegetation height (m; this study), $T_{c 0}$ was the minimal cropping time (1.13

532 s; van Gils et al., 2007), $c$ was a regression coefficient that described how cropping time

533 varied as a function of vegetation height $\left(0.0 \mathrm{~s} \mathrm{~m}^{-1}\right.$; Baveco et al., 2011), and $R_{\max }$ was the

534 maximal chewing rate $\left(0.06 \mathrm{~g} \mathrm{DM} \mathrm{s}^{-1}\right.$; van Gils et al., 2007). The instantaneous intake rate

$535\left(I_{C} ; \mathrm{g} \mathrm{DM} \mathrm{s}^{-1}\right)$ could then be estimated as:

$536 \quad I_{C}=S / T_{h}$

537 As accurate estimates of intake rate can be obtained from allometric scaling (van Gils et al., 2007; Wood et al., 2012), the intake rates were scaled for our swan species and age classes from the original values for adult Bewick's swans following the approach of Baveco et al.

540 (2011) and Wood et al. (2019b), using a mass exponent of 0.71 (van Gils et al., 2007).

541 Therefore, we modelled the intake rate $\left(I_{C} ; \mathrm{g} \mathrm{DM} \mathrm{hr}^{-1}\right)$ for swans feeding on wheat and 542 oilseed rape crops as:

$I_{C}=\left(\left(S / T_{h}\right) \cdot 3600\right) \cdot\left(M_{S} / M_{\text {Bewick,Adult }}\right)^{0.71}$,

544 where $M_{\text {Bewick,Adult }}$ was the mean winter body mass of an adult Bewick's swan $(6,000 \mathrm{~g}$; Kear, 545 2005), $M_{S}$ was the target mean body mass of the foraging swan species (Table 3). We 546 modified this equation so that intake rate was expressed for a given vegetation biomass $(B$, in $547 \mathrm{~g} \mathrm{DM} \mathrm{m}^{-2}$ ) rather than sward height $(H$, in $\mathrm{m})$, using the vegetation height and biomass data 548 from the fields in our study area. We used linear regression analyses, using R (R Core Team, 
549 2018), to estimate the relationship between the monthly mean height $(\mathrm{m})$ and biomass (g DM

$550 \mathrm{~m}^{-2}$ ) for (i) wheat, and (ii) oilseed rape:

$551 \quad H_{\text {Wheat }}=0.0366( \pm 0.0014) \cdot B_{\text {Wheat }}\left(F_{1,99}=663.8, P<0.001, R^{2}=87.0 \%\right)$,

$552 H_{O S R}=0.0328( \pm 0.0019) \cdot B_{O S R}\left(F_{1,99}=310.8, P<0.001, R^{2}=75.8 \%\right)$.

553 The functional response was therefore updated as:

554

$I_{C}=\left(\left(\left(b_{1} \cdot(z \cdot H)\right) /\left(1+\left(b_{2} \cdot(z \cdot H)\right)\right) /\left(T_{c 0}+c \cdot(z \cdot H)\right)+1 / R_{\max } \cdot\left(b_{1} \cdot(z \cdot H)\right) /\left(1+\left(b_{2} \cdot\right.\right.\right.\right.$

555

$(z \cdot H)))) \cdot 3600) \cdot\left(M_{S} / M_{\text {Bewick,Adult }}\right)^{0.71}$,

where $z$ was the mean slope estimate from equation 7 (for wheat) or equation 8 (for oilseed

557 rape).

558

The functional response for swans feeding on (i) sugar beet and (ii) potatoes, was adapted from that reported for adult Bewick's swans feeding on spilled wheat grains (Nolet et al., 2002):

561

$I_{\text {Root }}=((a \cdot B) /(1+a \cdot(1.82 \cdot B)) \cdot 3600) \cdot\left(M_{S} / M_{\text {Bewick,Adult }}\right)^{0.71}$,

562

563

564

565

566

567

568

569

570

where $M_{\text {Bewick,Adult }}$ was the mean body mass of an adult Bewick's swan (6,000g; Kear, 2005), $M_{S}$ was the target mean body mass of the foraging swan species (Table 3), and $a$ was the attack rate for Bewick's Swans feeding on sugar beet $\left(0.00114 \mathrm{~m}^{2} \mathrm{~s}^{-1}\right.$; van Gils and Tijsen, 2007). The functional response equation for swans feeding on spilled maize ( $I_{\text {Maize }}$ in $\mathrm{g}$ DM $\mathrm{hr}^{-1}$ ), was scaled from the functional response for barnacle geese (Branta leucopsis) feeding on maize reported by Clausen et al. (2018a):

$I_{\text {Maize }}=\left(\left((0.06064 \cdot B) /(1+(0.06064 \cdot(0.76204 \cdot B)) \cdot 60) \cdot\left(M_{S} / M_{\text {Barnacle }}\right)^{0.71}\right.\right.$,

where $M_{\text {Barnacle }}$ was the mean body mass of a barnacle goose $\left(2,050 \mathrm{~g}\right.$; Kear, 2005), $M_{S}$ was the target mean body mass of the foraging swan species (Table 3). 
571 To model the effects of interference competition, all intake rates were adjusted for the total

572 density of all swans on a given patch using a linear relationship $\left(R^{2}=95.5 \%\right)$ derived from

573 Gyimesi et al. (2010), who quantified how Bewick's Swan intake rate while feeding on plant

574 tubers declined with increasing numbers of competitors:

$575 \quad I_{\text {Prop }}=1.00-(17.29 \cdot D)$,

576 where $I_{\text {Prop }}$ was the proportion of the intake rate at a density of 1 individual ha ${ }^{-1}$ (equivalent to

5770.0001 individuals $\mathrm{m}^{-2}$ ) and $D$ was the patch density of swans (individuals $\mathrm{m}^{-2}$ ).

578 To prevent biologically implausible intake rates at high food densities, the maximum intake

579 rate $\left(I_{\max }\right.$ in $\left.\mathrm{g} \mathrm{hr}^{-1}\right)$ for each forager type was scaled from the maximum food consumption of

$580183 \mathrm{~g} \mathrm{DM}$ by adult mute swans in 24 hour feeding trials conducted by Mathiasson (1973):

$581 \quad I_{\max }=\left(\left(183 * M_{\text {Mute,Adult }}\right) / 24\right) *\left(M / M_{\text {Mute,Adult }}\right)^{\wedge 0.71}$,

582 where $M_{\text {Mute,Adult }}$ was the body mass of an adult mute swan and $M$ was the body mass $(\mathrm{g})$ of

583 the foraging swan species (Table 3). The amount of potential feeding time lost to disturbance $584(20.9 \%)$ was modelled as the time spent on vigilance behaviour, based on time-activity 585 budgets obtained for swans in our study area from 2015-2018 (Wood et al. 2019b). The energy content of each resource type obtained for our study area, adjusted for the swans' assimilation efficiency (i.e. the metabolisable proportion of the gross energy ingested that was extracted during the process of digestion and so was available to be used by the forager) using information obtained from the literature (Table 3), was used to convert a dry matter intake rate $\left(\mathrm{g} \mathrm{hr}^{-1}\right)$ into an energy intake rate $\left(\mathrm{kJ} \mathrm{hr}^{-1}\right)$.

591 We calculated the energetic cost of each behaviour as a multiple of the basal metabolic rate (BMR) of each forager type, based on the experimental measurements of Nolet et al. (2002) for foraging and resting, and from Nolet et al. (2016) for flight. The basal metabolic rate 
594

595

596

597

598

599

600

601

602

603

604

605

606

607

608

609

610

611

612

613

614

615

(BMR) of each forager type was calculated from the allometric equation presented by Hughes and Green (2005):

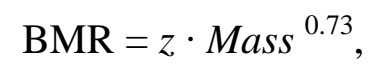

where $z$ represents the BMR value at $1 \mathrm{~kg}$ body mass (4.64 Watts for Anseriformes; Zar, 1968) and Mass was the body mass of the swan in kilograms (Table 3). We then calculated the behaviour-specific energetic costs determined for adult Bewick's swans by Nolet et al. (2002) as a proportion of adult Bewick's swan BMR. Finally, we multiplied these behaviourspecific proportions by the forager-specific BMR values to estimate the energetic cost of a given behaviour for each forager type (Table 3). No thermoregulatory energetic costs were added as the temperatures at our study site did not fall below the lower critical temperature for any of our forager types (Appendix A).

\subsection{Model validation and calibration}

Following model verification, we tested our baseline model's predictions against real-world data using the pattern-oriented modelling (POM) approach (Grimm and Railsback, 2012;

Chudzińska et al., 2016). POM compares observed and predicted values of multiple processes, at multiple levels of organisation. In this way, POM minimises the possibility that a model yields accurate predictions for incorrect mechanistic reasons (Grimm and Railsback, 2005). In total, four tests allowed us to assess the performance of our model: (i) proportions of swans that avoid starvation during winter; (ii) the proportion of swans that successfully departed from the study area at the end of winter; (iii) the number of minutes per day devoted to foraging; (iv) mean biomasses of each crop type at the end of winter (Appendix B). 
616 For all four tests, model predictions were validated against real-world data, with the accuracy

617 of the model predictions $(A)$ for each forager type calculated as:

$618 A=P / O$,

619 where $P$ and $O$ were the predicted and observed values for the given test, respectively. In the event of a mismatch between model predictions and real-world data, we had the option of using model calibration to adjust the values of key parameters until model predictions achieved a closer match to the real-world data (Grimm and Railsback, 2005). Mismatches in the swan starvation, emigration, or foraging effort tests could be addressed by amending the functional response equations to alter food intake rates. Mismatches in late winter crop biomasses could be addressed by alteration of the rates at which crop biomass changed per time step.

\subsection{Sensitivity analysis}

We used the individual parameter perturbation method (Hamby, 1994) to assess the relative influence of variation in the following parameter values to our model's predictions of the time spent foraging by swans, as previous models have shown that predicted foraging effort is typically the most sensitive of our four predictions (e.g. Wood et al., 2014; Stillman et al., 2015b): (i) resource biomass density, (ii) resource growth rate, (iii) resource gross energy content, (iv) forager assimilation efficiency, (v) swan arrival energy store, (vi) swan target energy store, (vii) swan BMR, (viii) swan intake rate, and (ix) the amount of time that field studies showed was lost to disturbance. For each parameter in turn, we performed simulations using (i) mean $-25 \%$, (ii) mean $-5 \%$ (ii) mean, (iii) mean $+5 \%$, and (v) mean $+25 \%$ values, for the parameter of interest, whilst simultaneously holding all other parameters at their mean 
values (Grimm and Railsback, 2005). The use of such fixed percentages in a sensitivity analysis is a commonly used approach in individual-based modelling (Revilla, 2020) as it allows the relative sensitivity of each parameter to be compared (Hamby, 1994; Mulligan and Wainright, 2004).

\subsection{Predictive scenarios}

We ran a series of simulations to predict how swans would respond to the independent and combined effects of increased competition and reduced food resources; specifically, postharvest remains of maize, sugar beet, and potatoes, as these crops are more likely to be reduced by the loss of subsidies to farmers, e.g. Poonyth et al. (2000). Simulations of increased competition were run with 1.0 (hereafter 'baseline'), 2.0, 3.0, 5.0, 10.0, and 12.0 times the number of individuals of each forager type present in the base simulations, based on historical changes in swan numbers (Frost et al., 2020); this increases could represent population growth or greater use of the study area by the existing populations. To simulate the losses of important food resources, we ran simulations with (i) $100 \%$ of the current postharvest crop remains present (Figure 3), (ii) $75 \%$ of post-harvest crop remains (iii) $50 \%$ of post-harvest crop remains, (iv) $25 \%$ of post-harvest crop remains, and (v) $0 \%$ of post-harvest crop remains (i.e. no maize, sugar beet, or potatoes). To assess the combined effects we performed simulations using each level of competition with each level of food loss (i.e. a total of 30 different scenarios). For each scenario the model predicted (i) the proportion of each forager type that would avoid starvation, (ii) the proportion of each forager type that would emigrate successfully at the end of winter, (iii) the foraging effort of individual swans, and (iv) the late winter (mid-March) biomasses of wheat and oilseed rape. 


\subsection{Model validation and calibration}

665

666

667

668

669

670

671

672

673

674

675

676

677

678

679

680

681

682

683

684

685

686

In line with our field observations, our baseline model correctly predicted that all individuals should avoid starvation and successfully emigrate from the study area at the end of winter (Figure 4a,b). However, the predicted time spent on foraging behaviour was lower than that observed in the field for all species and age classes (Figure 4c). Mean predicted foraging effort across all forager types was 81.1 minutes day ${ }^{-1}$, equivalent to $14.5 \%$ of daylight per day (based on a mean daylight period of 9.3 hours per day over winter; Table 2), compared with observations of 249.6 minutes day ${ }^{-1}$ or $44.7 \%$ of daylight per day. The disparity between predicted and observed values was smallest for Bewick's swans, for which predicted foraging times were, proportionally, 0.35 and 0.37 of observed values for adults and cygnets, respectively, while whooper swans showed the greatest difference, as predicted values were 0.30 and 0.29 of observed adult and cygnet values, respectively. The model predicted biomass densities closely matching observed values for each crop type (Figure 4d).

Given the mismatch between our initial model's predictions of foraging effort and the corresponding real-world data, we calibrated our model by adjusting the values of swan intake rates to improve model fit. As a starting point we calculated the predicted value as a proportion of the observed foraging effort $(A)$ for each forager type, as per equation 4 . Next we multiplied the crop-specific intake rates for each forager type by $A$ and re-ran the simulation, increasing $A$ by 0.01 each time until model predictions matched the observed data. As our initial model consistently underestimated foraging effort for all forager types, this step resulted in intake rates that were reduced according to the mismatch between predicted and observed values. The accuracy of this calibrated model was then assessed via the four tests to ensure that model fit had been improved; values of $A+0.02$ were found to 
687

688

689

690

691

692

693

694

695

696

697

698

699

700

701

702

703

704

705

706

707

708

709

give the best match between model predictions and observation (hereafter known as the calibrated model). The calibrated model also correctly predicted that all individuals should avoid starvation and successfully depart the study area at the end of winter (Figure 4a,b).

Predicted biomass densities also closely matched observed values for each crop type (Figure 4d). Our calibrated model predicted values of foraging effort for all forager types that were within the $95 \%$ CI values of the observed data, and the proportional accuracy did not exceed \pm 0.01 for all forager types (Figure $4 \mathrm{c}$ ). On account of its improved fit, this calibrated model was used in all subsequent simulations.

\subsection{Sensitivity analysis}

Variations of $\pm 5 \%$ and $\pm 25 \%$ in individual parameter values altered our calibrated model's predictions of foraging effort by between $\pm 0.4-6.4 \%$ and $\pm 2.1-42.1 \%$, respectively (Figure 5). Model predictions showed the greatest sensitivity to variations in resource gross energy values and assimilation efficiency. For example, we found that $-5 \%$ and $+5 \%$ changes in gross energy or assimilation efficiency values each resulted in mean changes (across all forager types) of $+6.4 \%$ and $-5.7 \%$, respectively, in the swans' foraging effort (Figure 5). Similarly, variations of $-25 \%$ and $+25 \%$ in gross energy or assimilation efficiency parameters resulted in mean changes (across all forager types) of $+42.1 \%$ and $-23.5 \%$, respectively, in foraging effort (Figure 5).

\subsection{Predictive scenarios}

Regardless of the numbers of competitors or the post-harvest crop remains available, all individuals were predicted by our calibrated model to avoid starvation and depart at the end 
of winter. However, individual foraging effort was predicted to vary considerably in response to changing levels of competition and food availability (Figure 6). The greatest predicted range in daily foraging times across simulations was shown by whooper swans; predicted daily foraging times for adult and cygnet whooper swans increased from 246.4 and 258.7 minutes, respectively, in baseline simulations (x1 swan densities and 100\% post-harvest crop remains), up to 355.2 and 377.3 minutes, respectively, at x12 competitor densities and $0 \%$ post-harvest remains (Figure 6). In contrast, mute swans were predicted to show much smaller increases in their daily foraging times, from 264.0 and 303.7 minutes for adults and cygnets, respectively, in baseline simulations, to 295.3 and 340.5 minutes for adults and cygnets, respectively, at x12 competitor densities and 0\% post-harvest remains (Figure 6). Bewick's swans were predicted to show intermediate increases in daily foraging times, from 221.3 and 213.7 minutes for adults and cygnets, respectively, in baseline simulations, to 314.8 and 306.4 minutes for adults and cygnets, respectively, at x12 competitor densities and 0\% post-harvest remains (Figure 6).

Wheat biomass in late winter remained relatively constant (mean $\pm 95 \% \mathrm{CI}=405.4 \pm 18.4 \mathrm{~g}$ $\mathrm{DM} \mathrm{m}{ }^{-2}$ ) between $\mathrm{x} 1-\mathrm{x} 3$ competitor densities, even in the absence of post-harvest crop remains, but declined to $373.7 \pm 5.2 \mathrm{~g} \mathrm{DM} \mathrm{m}^{-2}$ at the highest $\mathrm{x} 12$ competitor densities in the absence of post-harvest crop remains (Figure 7a). Oilseed rape biomass was predicted to show a greater relative decline from $939.5 \pm 18.2 \mathrm{~g} \mathrm{DM} \mathrm{m}^{-2}$ at baseline competitor densities with all crop types present, to $694.3 \pm 5.3 \mathrm{~g} \mathrm{DM} \mathrm{m}^{-2}$ in simulations with a twelve-fold increase in competitors and no post-harvest crop remains (Figure 7b).

\section{Discussion}


Avian herbivores feeding in agricultural landscapes face uncertain fluctuations in their food supplies, due to changes in farming practices and the conversion of agricultural land to other uses. Yet, our model predicted that individuals could buffer against increased competition and losses of food resources by increasing foraging effort to maintain energy reserves. At current forager densities and food resources, swan foraging effort was relatively low (only $45 \%$ of daylight hours), compared with $80-100 \%$ of daylight hours spent on foraging by some smaller-bodied avian herbivores (e.g. Brunckhorst, 1996; Dokter et al., 2018). Swans also show foraging effort that exceeds $45 \%$ during migratory stopovers (Nolet and Klaassen, 2005; Nuijten et al., 2020). Even when faced with no post-harvest crop remains and a twelvefold increase in competitors, swan foraging effort did not exceed 377 out of a mean 558 minutes $(68 \%)$ of daylight per day during the winter period. The capacity of swans to offset changes in conditions by increasing foraging time will have upper limits set by time availability and digestive constraints. Yet swans at stopover sites have been observed to exceed the maximum daily foraging effort of $68 \%$ predicted in our most extreme simulations, suggesting that the responses predicted in this study are indeed plausible (Nuijten et al., 2020). Species that already spend high percentages of their time foraging have limited scope for further increases to alleviate the impacts of environmental change. Our model predicted that whooper swans would show the greatest increases in foraging effort in response to lower food availability or increased competition, likely because they arrive first and so make greatest use of the post-harvest crop remains (Wood et al., 2019b). Mute swans do not begin to use the arable fields in our study area until mid-winter, by which time the post-harvest crop remains have typically been depleted (Wood et al., 2019b), and thus mute swans were predicted to show the smallest increases in foraging effort.

Calibration was required to obtain accurate predictions, which may reflect uncertainty in the values of certain model parameters. The functional response parameters in particular, were 
based on allometric scaling, in some cases from different crop types and over different ranges of crop biomasses, which was unavoidable given the relative scarcity of detailed experimental measurements of functional responses for large avian herbivores. Experimental measurements of lower critical temperature for large avian herbivores, rather than the allometric equation used here, would also help to more accurately quantify any thermoregulatory costs incurred during winter. The area represented in our model comprised only part of the entire winter ranges of the three swan species, but we considered it representative given the environmental conditions and food resources available (Beekman et al., 2019). The key factors affecting food loss and increased competition are widespread and so their effects would not be localised; reduced availability of crop remains is driven by changes in agricultural subsidies, whilst increased competition is linked to rising Whooper and Mute Swan numbers across their shared range. Therefore we expect that our finding that overwintering swans have low sensitivity to changes in food resources would apply more generally across the winter ranges.

Our model made the precautionary assumption that any individual that was unable to meet their energy requirements within our model area would starve, rather than disperse outside of our model to find alternative feeding areas. As food resources are typically super-abundant for avian herbivores wintering in temperate agricultural landscapes, there is little evidence to inform our understanding of how individuals would behave in a case of insufficient food resources. However, an earlier switch in the foraging habitats of swans overwintering at the Ouse Washes offers some evidence in favour of a dispersal response to food shortages. Due to a series of harsh winters which prevented swans feeding on grasses in flooded pasture fields on the Ouse Washes in the early 1970s, the swans began to range further from their central roost in search of food in the agricultural fields that surround the Ouse Washes; it was then that the swans began to feed on the high-energy arable crops that they feed on in the 
present day (Owen \& Cadbury, 1975). In actuality the conditions under which swans exhausted their food supply within our model area was not reached, even under the most extreme scenarios of competition and food loss, and so this assumption did not affect our conclusions.

Our findings support earlier work that suggests that swans in UK have low sensitivity to changes in winter food resources (e.g. Wood et al., 2018a, 2019a, 2019c). Swans, being large, have a relatively low metabolic rate and yet can achieve high energy intake rates (Bruinzeel et al., 1997), limiting their vulnerability to short-term reductions in food supply. As swans are generalist herbivores their dietary diversity also limits their vulnerability to the loss of any one food resource. At our study site, the gradual losses of post-harvest remains of maize, sugar beet, and potatoes over the course of winter are offset by the increasing biomasses of the autumn-sown wheat and oilseed rape, and thus food resources are available throughout the entire winter period (Wood et al. 2019c). Repeated studies of mortality among swans in the UK since the 1960s have shown that starvation has never been a major cause of mortality (Ogilvie, 1967; Owen and Cadbury, 1975; Hardman and Cooper, 1980; Birkhead, 1982; MacDonald et al., 1990; Brown et al., 1992; Wood et al., 2019a). Our model predicted no increased mortality even for Bewick's Swans, which were the competitively subdominant species. Our findings suggest that the recent c. $40 \%$ decline in Bewick's Swan numbers was unlikely to be linked to changes in winter food resources or competition (Beekman et al., 2019). This accords with earlier work by Wood et al. (2018a), which found that inter-annual variation in winter arable food resources had no effect on the survival rates of Bewick's swan adults or cygnets between the 1970s and 2010s. Over a similar time-period, increases in winter arable crops such as wheat and oilseed rape were shown to have had no effect on mute swan population size, indicating that mute swan population size had not been limited by winter arable food supplies (Wood et al., 2019a). 
Whilst the swans may be able to modify their behaviour to buffer against losses of food resources or increased competition, such effects were predicted to have consequences for the remaining crops. The loss of post-harvest maize, sugar beet, and potato crops was predicted to result in reduced late winter biomasses of oilseed rape and wheat, as the swans increased their exploitation of these latter crops. Swans were predicted to have greater impacts on oilseed rape, as the area devoted to this crop was smaller and the crop was preferred to wheat due to the higher biomasses and assimilation efficiency, which allowed a higher rate of energy gain for swans feeding on oilseed rape; hence oilseed rape was depleted more quickly by the swans. Future increases in crop damage could exacerbate existing conflicts associated with herbivore impacts, especially on oilseed rape as this crop type is particularly vulnerable to grazing damage by swans (Parrott and McKay, 2001; McKay and Parrott, 2002; Spray et al., 2002). Our results suggest that by continuing to provide post-harvest sugar beet, potatoes, and maize for overwintering swans, farmers would incur less damage to their activelygrowing wheat and oilseed rape crops.

Many authors have argued for conservation and related disciplines to become more predictive to address the challenges posed by a rapidly changing world (Mouquet et al., 2015; Stillman et al., 2015a; Wood et al., 2018b). The individual-based modelling approach demonstrated here offers a powerful tool for making and evaluating predictions of the impacts of environmental changes on wildlife populations.

\section{Acknowledgements}

We thank the landowners for granting access to the study area, Leigh Marshall and Louise Clewley for their support with fieldwork, Michelle O'Brien for useful discussions on avian energetics and physiology, and Laura Bonner and Andy Beer of Sparsholt College for 
undertaking the bomb calorimetry analyses. Uta Berger and two anonymous reviewers provided valuable feedback on our article. This study was funded by the Peter Scott Trust for Education and Research in Conservation, Peter Smith Charitable Trust for Nature, Olive Herbert Charitable Trust, D’Oyly Carte Charitable Trust, N. Smith Charitable Settlement, Robert Kiln Charitable Trust, the estate of the late Professor Geoffrey Matthews OBE, NWO grant 866.15.206, and all who supported WWT’s “Hope for Swans” Appeal.

\section{Appendix A. Swan energy adjustments for low temperature}

\section{Appendix B. Empirical data for model validation}

Supplementary data to this article can be found online.

\section{References}

Amano, T., Ushiyama, K., Fujita, G., Higuchi, H., 2004. Alleviating grazing damage by white-fronted geese: an optimal foraging approach. J. Appl. Ecol. 41, 675-688.

Bacon, P.J., Coleman, A.E., 1986. An analysis of weight changes in the Mute Swan Cygnus olor. Bird Study 33, 145-158.

Baveco, J.M., Kuipers, H., Nolet, B.A., 2011. A large-scale multi-species spatial depletion model for overwintering waterfowl. Ecol. Model. 222, 3773-3784.

Beekman, J., Koffijberg, K., Wahl, J., Kowallik, C., Hall, C., Devos, K., et al., 2019. Longterm population trends and shifts in distribution for Bewick's Swans Cygnus columbianus bewickii wintering in northwest Europe. Wildfowl Special Issue No. 5, 73-102. 
Bêty, J., Gauthier, G., Giroux, J.F., 2003. Body condition, migration, and timing of reproduction in snow geese: a test of the condition-dependent model of optimal clutch size. Am. Nat. 162, 110-121.

Birkhead, M., 1982. Causes of mortality in the mute swan Cygnus olor on the River Thames. J. Zool. 198, 15-25.

Black, J.M., Rees, E.C., 1984. The structure and behaviour of the Whooper Swan population wintering at Caerlaverock, Dumfries and Galloway, Scotland: an introductory study. Wildfowl 35, 21-36.

Blaxter, K.L. 1989. Energy metabolism in animals and man. Cambridge, UK, Cambridge University Press.

Brown, M.J., Linton, E., Rees, E.C., 1992. Causes of mortality among wild swans in Britain. Wildfowl 43, 70-79.

Bruinzeel, L.W., van Eerden, M.R., Drent, R.H., Vulink, J.T., 1997. Scaling metabolisable energy intake and daily energy expenditure in relation to the size of herbivorous waterfowl: limits set by available foraging time and digestive performance, in: van Eerden, M.R. (Ed.), Patchwork: patch use, habitat exploitation and carrying capacity for water birds in Dutch freshwater wetlands. Lelystad, The Netherlands, pp. 111-132.

Brunckhorst, H., 1996. Ökologie und Energetik der Pfeifente (Anas penelope L. 1758) im Schleswig-Holsteinischen Wattenmeer. Hamburg, Germany, Kovač.

Butkauskas, D., Švažas, S., Tubelyt, V., Morkŭnas, J., Sruoga, A., Boiko, D., Paulauskas, A., Stanevičius, V., Baublys, V., 2012. Coexistence and population genetic structure of the Whooper Swan Cygnus cygnus and Mute Swan Cygnus olor in Lithuania and Latvia. Central Eur. J. Biol. 7, 886-894. 
876 Cantelaube, P., Terres, J.M., 2005. Seasonal weather forecasts for crop yield modelling in 877 Europe. Tellus A. 57, 476-487.

878 Chudzińska, M., Ayllón, D., Madsen, J., Nabe-Nielsen, J., 2016. Discriminating between 879 possible foraging decisions using pattern-oriented modelling: the case of pink-footed geese in 880 Mid-Norway during their spring migration. Ecol. Model. 320, 299-315.

881 Clausen, K.K., Madsen, J., Nolet, B.A., Haugaard, L., 2018a. Maize stubble as foraging 882 habitat for wintering geese and swans in northern Europe. Agric. Ecosyst. Environ. 259, $72-$ 883 76.

Clausen, K.K., Madsen, J., Cottaar, F., Kuijken, E., Verscheure, C., 2018b. Highly dynamic 885 wintering strategies in migratory geese: Coping with environmental change. Glob. Change Biol. 24, 3214-3225.

887

Dokter, A.M., Fokkema, W., Bekker, S.K., Bouten, W., Ebbinge, B.S., Müskens, G., et al., 888 2018. Body stores persist as fitness correlate in a long-distance migrant released from food 889 constraints. Behav. Ecol. 29, 1157-1166.

890

Döös, B.R., 2002. Population growth and loss of arable land. Glob. Environ. Change 12, 891 $303-311$.

892

Drent, R.H., Fox, A.D., Stahl, J., 2006. Travelling to breed. J. Ornithol. 147, 122-134.

Durant, D., Fritz, H., Blais, S., Duncan, P., 2003. The functional response in three species of 894 herbivorous Anatidae: effects of sward height, body mass and bill size. J. Anim. Ecol. 72,

895 $220-231$.

Evans, M.E.. Kear, J., 1978. Weights and measurements of Bewick's Swans during winter.

897 Wildfowl 29, 118-122. 
898

899

900

901

902

903

904

905

906

907

908

909

910

911

912

913

914

915

916

917

918

919

Fretwell, S.D., Lucas Jr., H.L., 1970. On territorial behavior and other factors influencing habitat distribution in birds. I. Theoretical Development. Acta Biotheor. 19: 16-36.

Frost, T.M., Calbrade, N.A., Birtles, G.A., Mellan, H.J., Hall, C., Robinson, A.E., et al., 2020. Waterbirds in the UK 2018/19: The Wetland Bird Survey. BTO/RSPB/JNCC, Thetford, UK.

Grafen, A., 1999. Formal Darwinism, the individual-as-maximizing-agent analogy and bethedging. Proc. Royal Soc. B 266, 799-803.

Grimm, V., Railsback, S.F., 2005. Individual-based Modeling and Ecology. Princeton University Press, Princeton, USA.

Grimm, V., Railsback, S.F., 2012. Pattern-oriented modelling: a 'multi-scope' for predictive systems ecology. Philos. Trans. Royal Soc. B 367, 298-310.

Grimm, V., Railsback, S.F., Vincenot, C.E., Berger, U., Gallagher, C., DeAngelis, D.L., et al., 2020. The ODD protocol for describing agent-based and other simulation models: a second update to improve clarity, replication, and structural realism. J. Artif. Soc. Soc. Simul. 23,7 .

Gyimesi, A., Stillman, R.A., Nolet, B.A., 2010. Cryptic interference competition in swans foraging on cryptic prey. Anim. Behav. 80, 791-797.

Hall, C., Crowe, O., McElwaine, G., Einarsson, Ó., Calbrade, N., Rees, E.C., 2016.

Population size and breeding success of the Icelandic Whooper Swan Cygnus cygnus: results of the 2015 international census. Wildfowl 66, 75-97.

Hamby, D.M., 1994. A review of techniques for parameter sensitivity analysis of environmental models. Environ. Monit. Assess. 32, 135-154. 
Hardman, J.A., Cooper, D.R., 1980. Mute Swans on the Warwickshire Avon-a study of a decline. Wildfowl 31, 29-36.

Harrison, X.A., Blount, J.D., Inger, R., Norris, D.R., Bearhop, S., 2011. Carry-over effects as drivers of fitness differences in animals. J. Anim. Ecol. 80, 4-18.

Holling, C.S., 1959. Some characteristics of simple types of predation and parasitism. Can. Entomol. 91, 385-398.

Hughes, B., Green, A.J., 2005. Feeding ecology, in: Kear, J. (Ed.), Ducks, Geese and Swans. Oxford, UK, Oxford Univ. Press, pp. 27-56.

Inger, R., Harrison, X.A., Ruxton, G.D., Newton, J., Colhoun, K., Gudmundsson, G.A., et al., 2010. Carry-over effects reveal reproductive costs in a long-distance migrant. J. Anim. Ecol. 79, 974-982.

Kear, J., 2005. Ducks, Geese and Swans. Oxford, UK, Oxford University Press.

MacDonald, J.W., LiGoater, R., Atkinson, N.K., Small, J., 1990. Further causes of death in Scottish swans (Cygnus spp.). State Veterinary J. 44, 81-93.

Madsen, J., 2015. Too many geese?, in: Redpath, S.M., Gutiérrez, R.J., Wood, K.A., Young, J.C. (Eds.), Conflicts in Conservation: Navigating towards solutions. Cambridge, UK, Cambridge University Press, pp. 105-107.

Madsen, J., Klaassen, M., 2006. Assessing body condition and energy budget components by scoring abdominal profiles in free-ranging pink-footed geese Anser brachyrynchus. J. Avian Biol. 37, 283-287.

Maris, V., Huneman, P., Coreau, A., Kéfi, S., Pradel, R., Devictor, V. 2018. Prediction in ecology: promises, obstacles and clarifications. Oikos 127, 171-183. 
Mathiasson, S., 1973. A moulting population of non-breeding Mute Swans with special reference to flight-feather moult, feeding ecology and habitat selection. Wildfowl 24, 43-53.

McKay, H.V., Parrott, D., 2002. Mute swan grazing on winter crops: evaluation of three grazing deterrents on oilseed rape. Int. J. Pest Manage. 48, 189-194.

Milinski, M., Boltshauser, P., Buchi, L., Buchwalder, T., Frischknecht, M., Hadermann, T., Kunzler, R., Roden, C., Ruetsch, A., Strahm, D., Tognola, M. 1995. Competition for food in swans: an experimental test of the truncated phenotype distribution. J. Anim. Ecol. 64, 758766.

Mouquet, N., Lagadeuc, Y., Devictor, V., Doyen, L., Duputié, A., Eveillard, D., et al., 2015. Predictive ecology in a changing world. J. Appl. Ecol. 52, 1293-1310.

Mulligan, M., Wainwright, J., 2004. Modelling and model building. In: Mulligan, M., Wainwright, J. (Eds.), Environmental Modelling: Finding Simplicity in Complexity. John Wiley and Sons, Chichester, UK, pp. 7-73.

Nagy, S., Petkov, N., Rees, E.C., Solokha, A., Hilton, G., Beekman, J., Nolet, B., 2012. International Single Species Action Plan for the Conservation of the Northwest European Population of Bewick's Swan (Cygnus columbianus bewickii). AEWA Technical Series No. 44. Bonn, Germany, AEWA.

Newton, I., 2017. Farming and Birds. London, UK, William Collins.

Nolet, B.A., Klaassen, M., 2005. Time and energy constraints in demanding phases of the annual cycle: an example of time limitation in refuelling migratory swans. Oikos 111: 302310. 
Nolet, B.A., Klaassen, M. 2009. Retrodicting patch use by foraging swans in a heterogeneous environment using a set of functional responses. Oikos 118, 431-439.

Nolet, B.A., Bevan, R.M., Klaassen, M., Langevoord, O., Van der Heijden, Y.G.J.T., 2002.

Habitat switching by Bewick's swans: maximization of average long-term energy gain? J. Anim. Ecol. 71, 979-993.

Nolet, B.A., Gyimesi, A., van Krimpen, R.R., de Boer, W.F., Stillman, R.A., 2016. Predicting effects of water regime changes on waterbirds: insights from staging swans. PLoS One 11, $\mathrm{e} 0147340$.

Nuijten, R.J.M., Prins, E.F., Lammer, J., Mager, C., Nolet, B.A., 2020. Calibrating tri-axial accelerometers for remote behavioural observations in Bewick's swans. J. Zoo Aquar. Res. 8, $231-238$

Ogilvie, M.A., 1967. Population changes and mortality of the Mute Swan in Britain. Wildfowl 18, 64-73.

Owen, M. 1976. The selection of winter food by whitefronted geese. J. Appl. Ecol. 13, 715729.

Owen, M., Cadbury, C.J., 1975. The ecology and mortality of swans at the Ouse Washes, England. Wildfowl 26, 31-42.

Parrott, D., McKay, H.V., 2001. Mute swan grazing on winter crops: estimation of yield loss in oilseed rape and wheat. Crop Protection 20, 913-919.

Petkov, N., Harrison, A.L., Stamenov, A., Hilton, G.M., 2017. The impact of wintering geese on crop yields in Bulgarian Dobrudzha: implications for agri-environment schemes. Eur. J. Wildlife Res. 63, 66. 

subsidized EU sugar exports. Agr. Econ. 22, 233-245.

Pot, M.T., de Koning, S., Westerduin, C., de Boer, W.F., Shariati, M., Lameris, T.K., 2019.

Wintering geese trade-off energetic gains and costs when switching from agricultural to natural habitats. Ardea 107, 1-14.

990

R Core Team., 2018. R: a language and environment for statistical computing. [3.5.1].

Vienna, Austria, R Foundation for Statistical Computing.

Rees, E.C., 2006. Bewick’s swan. London, UK, T.\&A.D. Poyser.

Rees, E.C., Kirby, J.S., Gilburn, A., 1997. Site selection by swans wintering in Britain and Ireland; the importance of habitat and geographic location. Ibis 139, 337-352.

Revilla, E., 2020. Individual and Agent-based Models in Population Ecology and Conservation Biology. In: Murray, D.L., Sandercock, B.K. (Eds.), Population Ecology in Practice. John Wiley and Sons, Chichester, UK, pp. 237-260.

Scheffer, M., Baveco, J. M., DeAngelis, D.L., Rose, K.A., van Nes, E., 1995. Superindividuals a simple solution for modelling large populations on an individual basis. Ecol.

1000 Model. 80, 161-170.

1001

Scott, D.K., 1980. Functional aspects of prolonged parental care in Bewick's swans. Anim. Behav. 28, 938-952.

Sih, A., Christensen, B., 2001. Optimal diet theory: when does it work, and when and why does it fail? Anim Behav 61: 379-390. models of functional response. Am. Nat. 140, 325-348. 
Spray, C.J., Morrison, N., Chisholm, H., 2002. Utilisation of oilseed rape fields by mute swans Cygnus olor in Scotland and implications for management. Aspect. Appl. Biol. 67, 6774.

Stillman, R.A., 2008. MORPH - An individual-based model to predict the effect of environmental change on foraging animal populations. Ecol. Model. 216, 265-276.

Stillman, R.A., Railsback, S.F., Giske, J., Berger, U., Grimm, V., 2015a. Making predictions in a changing world: the benefits of individual-based ecology. BioScience 65, 140-150.

Stillman, R.A., Wood, K.A., Gilkerson, W., Elkinton, E., Black, J.M., Ward, D.H. et al., 2015b. Predicting effects of environmental change on a migratory herbivore. Ecosphere 6, 114.

Sutherland, W.J., 2006. Predicting the ecological consequences of environmental change: a review of the methods. J. Appl. Ecol. 43, 599-616.

USNO., 2018. United States Naval Observatory Astronomical Applications Department Calculator. http://aa.usno.navy.mil/data/docs/RS_OneYear.php Accessed 10th October 2018. van Gils, J.A., Tijsen, W., 2007. Short-term foraging costs and long-term fueling rates in central-place foraging swans revealed by giving-up exploitation times. Am. Nat., 169, 609620.

van Gils, J.A., Gyimesi, A., van Lith, B., 2007. Avian herbivory: an experiment, a field test, and an allometric comparison with mammals. Ecology 88, 2926-2935.

Ward, R.M., Cranswick, P.A., Kershaw, M., Austin, G.E., Brown, A.W., Brown, L.M., et al., 2007. Numbers of mute swans Cygnus olor in Great Britain: results of the national census in 2002. Wildfowl 57, 3-20. 
Wood, K.A., Stillman, R.A., Clarke, R.T., Daunt, F., O’Hare, M.T., 2012. The impact of waterfowl herbivory on plant standing crop: a meta-analysis. Hydrobiologia 686, 157-167.

Wood, K.A., Stillman, R.A., Wheeler, D., Groves, S., Hambly, C., Speakman, J.R., Daunt, F., O'Hare, M.T., 2013. Go with the flow: water velocity regulates herbivore foraging decisions in river catchments. Oikos 122, 1720-1729.

Wood, K.A., Stillman, R.A., Daunt, F., O’Hare, M.T., 2014. Can sacrificial feeding areas protect aquatic plants from herbivore grazing? Using behavioural ecology to inform wildlife management. PLoS One 9, e104034.

Wood, K.A., Nuijten, R.J., Newth, J.L., Haitjema, T., Vangeluwe, D., Ioannidis, P., et al., 2018a. Apparent survival of an Arctic-breeding migratory bird over 44 years of fluctuating population size. Ibis 160, 413-430.

Wood, K.A., Stillman, R.A., Hilton, G.M., 2018b. Conservation in a changing world needs predictive models. Anim. Conserv. 21, 87-88.

Wood, K.A., Brown, M.J., Cromie, R.L., Hilton, G.M., Mackenzie, C., Newth, J.L., et al., 2019a. Regulation of lead fishing weights results in mute swan population recovery. Biol. Conserv. 230, 67-74.

Wood, K.A., Hilton, G.M., Newth, J.L., Rees, E.C., 2019b. Seasonal variation in energy gain explains patterns of resource use by avian herbivores in an agricultural landscape: Insights from a mechanistic model. Ecol. Model. 409, 108762.

Wood, K.A., Newth, J.L., Brides, K., Burdekin, M., Harrison, A.L., Heaven, S., et al., 2019c. Are long-term trends in Bewick's Swan (Cygnus columbianus bewickii) numbers driven by changes in winter food resources? Bird Conserv. Int. 29, 479-496. 
Zar, J.H., 1968. Standard metabolism comparisons between orders of birds. Condor 70, 278. 
1054 Table 1: A summary of the state variables used to describe the entities featured in our model.

\begin{tabular}{|c|c|c|}
\hline Entity & State variables & Description \\
\hline \multirow[t]{3}{*}{ Global } & Time & Modelled as discrete one hour increments \\
\hline & Day & $\begin{array}{l}24 \text { hourly time steps in the model used to } \\
\text { represent a standard } 24 \text { hour day }\end{array}$ \\
\hline & Daylight & Binary description of whether daylight or not \\
\hline \multirow[t]{3}{*}{ Patches } & Location & Central co-ordinates \\
\hline & Size & Area $\left(\mathrm{m}^{2}\right)$ \\
\hline & Type & Field $(n=60)$ or roost $(n=1)$ patch \\
\hline \multirow[t]{2}{*}{ Resources } & Biomass density in patch & $\begin{array}{l}\text { The biomass density }\left(\mathrm{g} \mathrm{DM} \mathrm{m}^{-2}\right) \text { of each crop } \\
\text { type within each patch }\end{array}$ \\
\hline & Biomass density change & $\begin{array}{l}\text { Temporal change in the biomass density of each } \\
\text { crop type in the absence of depletion by swans; } \\
\text { represents temporal pattern of growth or } \\
\text { senescence }\end{array}$ \\
\hline Component & Energy content in resource & $\begin{array}{l}\text { The energy content }\left(\mathrm{kJ} \mathrm{g}^{-1} \mathrm{DM}\right) \text { of each crop } \\
\text { type }\end{array}$ \\
\hline \multirow[t]{11}{*}{ Swans } & Swan type & $\begin{array}{l}\text { The species and age class to which the swan } \\
\text { belongs }\end{array}$ \\
\hline & Arrival day & $\begin{array}{l}\text { Day on which each swan species arrives (i.e. is } \\
\text { created) within the model }\end{array}$ \\
\hline & Arrival energy store & $\begin{array}{l}\text { The amount of energy that each swan possesses } \\
\text { within its body reserves when it arrives }\end{array}$ \\
\hline & Departure energy store & $\begin{array}{l}\text { The target amount of energy that a swan must } \\
\text { contain }\end{array}$ \\
\hline & Current energy store & $\begin{array}{l}\text { The amount of energy within the body reserves } \\
\text { of an individual swan during the current time } \\
\text { step }\end{array}$ \\
\hline & Assimilation efficiency & $\begin{array}{l}\text { The proportion of the energy content in each } \\
\text { crop type that can be assimilated by foraging } \\
\text { swans; specific value for each crop type }\end{array}$ \\
\hline & Anabolism efficiency & $\begin{array}{l}\text { Proportional efficiency with which swans add } \\
\text { energy to their internal energy store }\end{array}$ \\
\hline & Time lost to disturbance & $\begin{array}{l}\text { The proportion of the total potential foraging } \\
\text { time available in each time step lost to sources } \\
\text { of disturbance }\end{array}$ \\
\hline & Dominance rank & $\begin{array}{l}\text { Score denoting dominance hierarchy for } \\
\text { foraging interactions }\end{array}$ \\
\hline & Flight cost & $\begin{array}{l}\text { Energetic cost }(\mathrm{kJ}) \text { of flying between roost and } \\
\text { feeding area; specific to each species and age } \\
\text { class }\end{array}$ \\
\hline & Patch & $\begin{array}{l}\text { Patch number being used by the individual } \\
\text { during the current time step }\end{array}$ \\
\hline
\end{tabular}


Diet

Proportion of time feeding

Diet consumption rate

Component consumption

rate

Component assimilation rate

Component metabolic rate
The crop type being consumed during the current time step

The proportion of the current time step spent on foraging

The rate at which diet (i.e. crop type) is consumed during current time step The rate at which a component (i.e. energy) is consumed during current time step

The rate at which a component (i.e. energy) is assimilated during current time step

Rate at which a component is metabolised during current time step

1055

1056 
1057 Table 2: A summary of the patch and resource parameter values and their derivation.

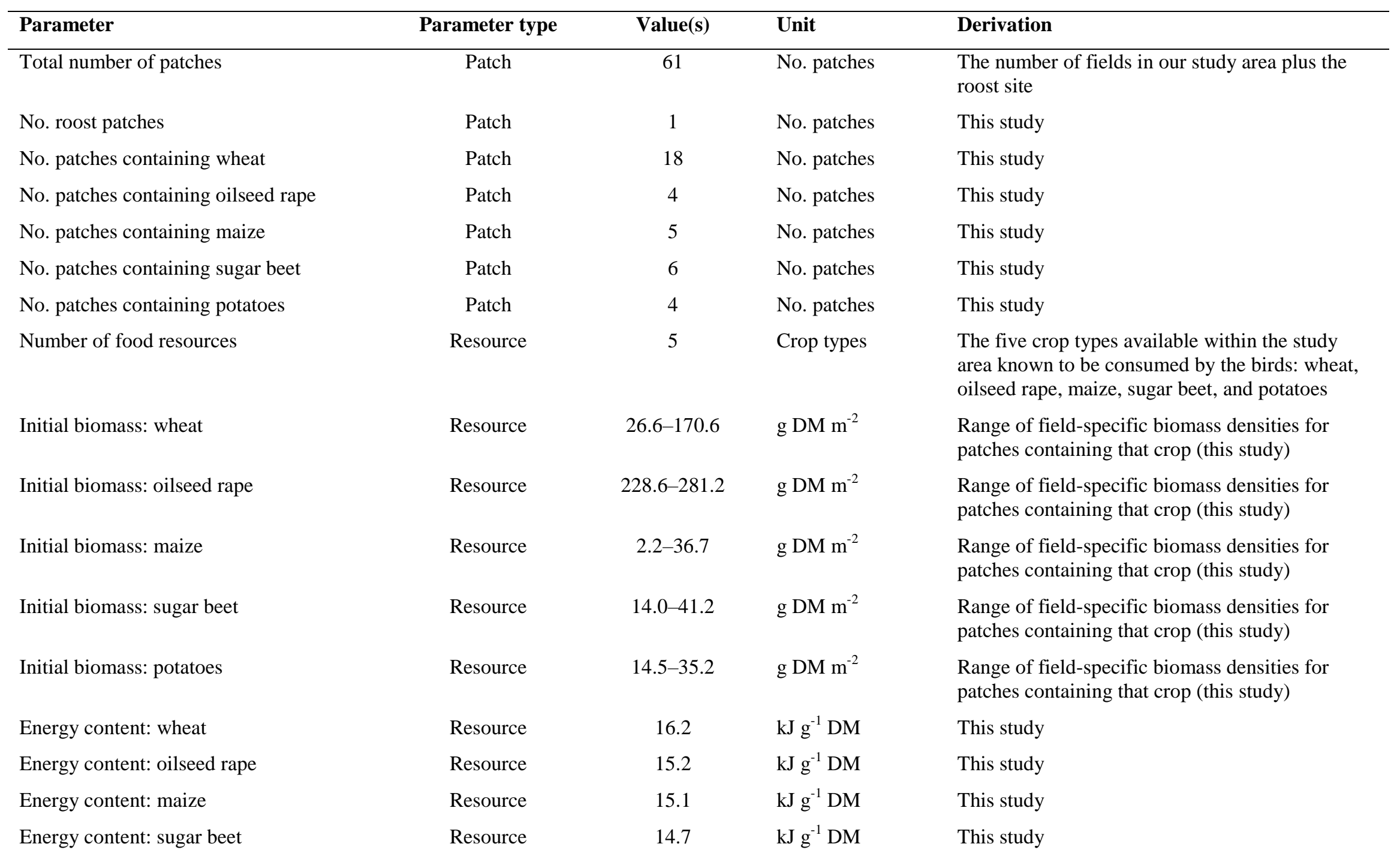




\section{Energy content: potatoes}

Biomass change: wheat (November)

Biomass change: wheat (December)

Biomass change: wheat (January)

Biomass change: wheat ( $\geq$ February)

Biomass change: oilseed rape (November)

Biomass change: oilseed rape (December)

Biomass change: oilseed rape (January)

Biomass change: oilseed rape ( $\geq$ February)

Biomass change: maize (November)

Biomass change: maize (December)

Biomass change: maize (January)

Biomass change: maize ( $\geq$ February)

Biomass change: sugar beet (November)

Biomass change: sugar beet (December)

Biomass change: sugar beet (January)

Biomass change: sugar beet ( $\geq$ February)

Biomass change: potatoes (November)

Biomass change: potatoes (December)

Biomass change: potatoes (January)

Biomass change: potatoes ( $\geq$ February)

\begin{tabular}{|c|c|c|c|}
\hline Resource & 15.2 & $\mathrm{~kJ} \mathrm{~g}^{-1} \mathrm{DM}$ & This study \\
\hline Resource & 0.0795 & $\mathrm{~g} \mathrm{DM} \mathrm{hr}{ }^{-1}$ & This study \\
\hline Resource & 0.0050 & $\mathrm{~g} \mathrm{DM} \mathrm{hr}^{-1}$ & This study \\
\hline Resource & 0.0068 & $\mathrm{~g} \mathrm{DM} \mathrm{hr}^{-1}$ & This study \\
\hline Resource & 0.0850 & $\mathrm{~g} \mathrm{DM} \mathrm{hr}^{-1}$ & This study \\
\hline Resource & 0.0606 & $\mathrm{~g} \mathrm{DM} \mathrm{hr}{ }^{-1}$ & This study \\
\hline Resource & 0.0186 & $\mathrm{~g} \mathrm{DM} \mathrm{hr}{ }^{-1}$ & This study \\
\hline Resource & 0.0044 & $\mathrm{~g} \mathrm{DM} \mathrm{hr}^{-1}$ & This study \\
\hline Resource & 0.2133 & $\mathrm{~g} \mathrm{DM} \mathrm{hr}{ }^{-1}$ & This study \\
\hline Resource & -0.0087 & $\mathrm{~g} \mathrm{DM} \mathrm{hr}{ }^{-1}$ & This study \\
\hline Resource & -0.0016 & g DM hr ${ }^{-1}$ & This study \\
\hline Resource & -0.0004 & $\mathrm{~g} \mathrm{DM} \mathrm{hr}{ }^{-1}$ & This study \\
\hline Resource & -0.0002 & $\mathrm{~g} \mathrm{DM} \mathrm{hr}^{-1}$ & This study \\
\hline Resource & -0.0155 & $\mathrm{~g} \mathrm{DM} \mathrm{hr}^{-1}$ & This study \\
\hline Resource & -0.0117 & $\mathrm{~g} \mathrm{DM} \mathrm{hr}{ }^{-1}$ & This study \\
\hline Resource & -0.0026 & g DM hr ${ }^{-1}$ & This study \\
\hline Resource & -0.0015 & $\mathrm{~g} \mathrm{DM} \mathrm{hr}{ }^{-1}$ & This study \\
\hline Resource & -0.0074 & $\mathrm{~g} \mathrm{DM} \mathrm{hr}^{-1}$ & This study \\
\hline Resource & -0.0065 & $\mathrm{~g} \mathrm{DM} \mathrm{hr}{ }^{-1}$ & This study \\
\hline Resource & -0.0019 & $\mathrm{~g} \mathrm{DM} \mathrm{hr}{ }^{-1}$ & This study \\
\hline Resource & -0.0001 & g DM hr ${ }^{-1}$ & This study \\
\hline
\end{tabular}

1058 
1059 Table 3: A summary of the key information associated with forager types that was used to parameterize our model. * indicates information was

1060 used to derive parameter values, but was not a parameter itself.

\begin{tabular}{|c|c|c|c|c|c|c|c|c|}
\hline Parameter & $\begin{array}{l}\text { Bewick's } \\
\text { Swan } \\
\text { (adults) }\end{array}$ & $\begin{array}{c}\text { Bewick's } \\
\text { Swan } \\
\text { (cygnets) }\end{array}$ & $\begin{array}{l}\text { Whooper } \\
\text { Swan } \\
\text { (adults) }\end{array}$ & $\begin{array}{l}\text { Whooper } \\
\text { Swan } \\
\text { (cygnets) }\end{array}$ & $\begin{array}{l}\text { Mute } \\
\text { Swan } \\
\text { (adults) }\end{array}$ & $\begin{array}{l}\text { Mute } \\
\text { Swan } \\
\text { (cygnets) }\end{array}$ & Unit & Derivation \\
\hline Total number of individuals & 101 & 15 & 220 & 52 & 15 & 5 & No. individuals & $\begin{array}{l}\text { Peak numbers of individuals observed } \\
\text { during this study }\end{array}$ \\
\hline Arrival date of first individual & $15^{\text {th }}$ Nov & $15^{\text {th }}$ Nov & $1^{\text {st }}$ Nov & $1^{\text {st }}$ Nov & $1^{\text {st }} \mathrm{Jan}$ & $1^{\text {st }}$ Jan & - & $\begin{array}{l}\text { Owen \& Cadbury (1975); Rees (2006); } \\
\text { Wood et al. (2019c) }\end{array}$ \\
\hline Departure date of first individual & $1^{\text {st }} \mathrm{Feb}$ & $1^{\text {st }} \mathrm{Feb}$ & $1^{\text {st }}$ Mar & $1^{\text {st }}$ Mar & $30^{\text {th }}$ Mar & $30^{\text {th }}$ Mar & - & $\begin{array}{l}\text { Field data (Owen \& Cadbury 1975; Rees } \\
\text { 2006; Wood } \text { et al. 2019c) }\end{array}$ \\
\hline Body mass on arrival* & 5125 & 4392 & 8285 & 7076 & 10260 & 8360 & g & $\begin{array}{l}\text { Estimated mean body mass in autumn/early } \\
\text { winter (after: Evans \& Kear 1978; Bacon \& } \\
\text { Coleman 1986) }\end{array}$ \\
\hline Target body mass on departure* & 6000 & 5400 & 9700 & 8700 & 10800 & 8800 & $\mathrm{~g}$ & $\begin{array}{l}\text { Mean body mass at end of winter (Kear } \\
\text { 2005) }\end{array}$ \\
\hline Lean mass* & 4150 & 3500 & 6400 & 5400 & 8400 & 6800 & g & $\begin{array}{l}\text { Minimum reported body mass of live } \\
\text { individuals (Kear 2005; Rees 2006) }\end{array}$ \\
\hline Energy density & 27.5 & 27.5 & 27.5 & 27.5 & 27.5 & 27.5 & $\mathrm{~kJ} \mathrm{~g}^{-1}$ & $\begin{array}{l}\text { Energy content of avian energy storage } \\
\text { tissues (Madsen \& Klaassen 2006) }\end{array}$ \\
\hline Energy store on arrival & 26810 & 24535 & 51844 & 46098 & 51150 & 42900 & $\mathrm{~kJ}$ & (arrival mass - lean mass) $*$ energy density \\
\hline Target energy store on departure & 50875 & 52250 & 90750 & 90750 & 66000 & 55000 & $\mathrm{~kJ}$ & $\begin{array}{l}\text { (departure mass - lean mass) * energy } \\
\text { density }\end{array}$ \\
\hline Basal metabolic rate (BMR) & 61.8 & 57.2 & 87.7 & 81.0 & 94.9 & 81.7 & $\mathrm{~kJ} \mathrm{hr}^{-1}$ & $\begin{array}{l}\text { Calculated from the allometric equation } \\
\text { presented by Hughes and Green (2005) }\end{array}$ \\
\hline Resting energetic cost & 1.26 & 1.26 & 1.26 & 1.26 & 1.26 & 1.26 & $\mathrm{xBMR}$ & $\begin{array}{l}\text { The energetic cost of resting reported by } \\
\text { Nolet et al. (2002) for adult Bewick's swans, } \\
\text { expressed as a multiple BMR. }\end{array}$ \\
\hline
\end{tabular}


Energy expenditure whilst resting

Foraging energetic cost

Energy expenditure whilst foraging

94.0

87.0

133.4

Flying energetic cost

Energy expenditure whilst flying

Energy expenditure on daily flights

Assimilation efficiency: wheat

Assimilation efficiency: oilseed rape

Assimilation efficiency: maize

Assimilation efficiency: sugar beet

Assimilation efficiency: potatoes

Anabolism efficiency
678

220.4
11

1040

338.8
123.2

144.3

124.3

$\mathrm{kJ} \mathrm{hr}^{-1}$

120.0

103.3

$\mathrm{kJ} \mathrm{hr}$

$\mathrm{BMR}$

\section{$\mathrm{BMR}$}

961

313.
1126

366.8
$\mathrm{kJ} \mathrm{hr}^{-1}$

$\mathrm{kJ}$

$\begin{array}{lllllll}0.63 & 0.63 & 0.63 & 0.63 & 0.63 & 0.63 & \text { Proportion } \\ 0.73 & 0.73 & 0.73 & 0.73 & 0.73 & 0.73 & \text { Proportion } \\ 0.81 & 0.81 & 0.81 & 0.81 & 0.81 & 0.81 & \text { Proportion } \\ 0.84 & 0.84 & 0.84 & 0.84 & 0.84 & 0.84 & \text { Proportion } \\ 0.89 & 0.89 & 0.89 & 0.89 & 0.89 & 0.89 & \text { Proportion } \\ 0.80 & 0.80 & 0.80 & 0.80 & 0.80 & 0.80 & \text { Proportion }\end{array}$

Calculated as the XBMR cost of resting multiplied by BMR.

The energetic cost of foraging reported by Nolet et al. (2002) for adult Bewick's swans, expressed as a multiple BMR.

Calculated as the $\mathrm{xBMR}$ cost of foraging multiplied by BMR. An extra cost, based on the energy expenditure required to undertake a daily return flight between the roost and feeding area was added to the basic cost of foraging shown here (see below).

Flight cost of Nolet et al. (2016), expressed as a multiple of BMR.

Calculated as the xBMR cost of flying multiplied by BMR.

Flight costs as a multiple of BMR (based on Nolet et al. (2016) multiplied by total daily time spent in flight (586 s). Flight time calculated as $2 \mathrm{x}$ distance between roost and feeding area $(2 \times 7.5 \mathrm{~km})$ divided by flight speed (12.8 $\mathrm{m} \mathrm{s}^{-1}$; Nolet et al., 2002). This expenditure was modelled as an additional cost incurred by all foraging birds, spread over 9 time steps (as foraging only occurred during daylight and the mean number of daylight time steps per day was 9).

Amano et al. (2004)

Brunckhorst (1996)

Clausen et al. (2018)

Nolet et al. (2002)

Nolet (unpubl. data)

Blaxter (1989) 
Catabolism efficiency

Maximum intake rate

1061
1.00

54.3
1.00

50.3
76.3
1.00
70.6

1.00

82.4
Proportion

$\mathrm{g} \mathrm{hr}^{-1}$
Blaxter (1989)

Scaled from Mathiasson (1973) 


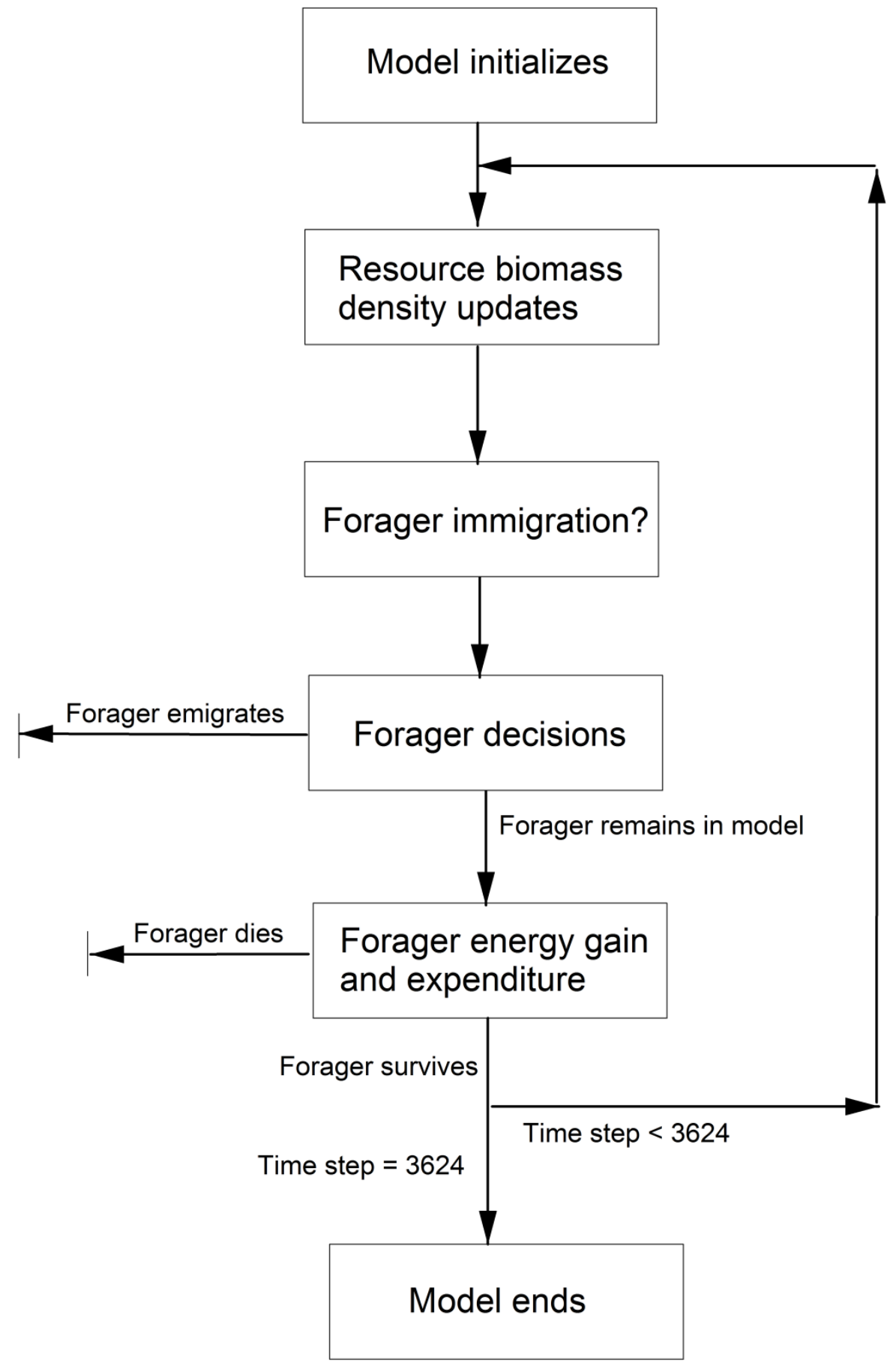

1064 Figure 1: A concept diagram to illustrate the scheduling of the processes and submodels that 1065 occur within our model. 


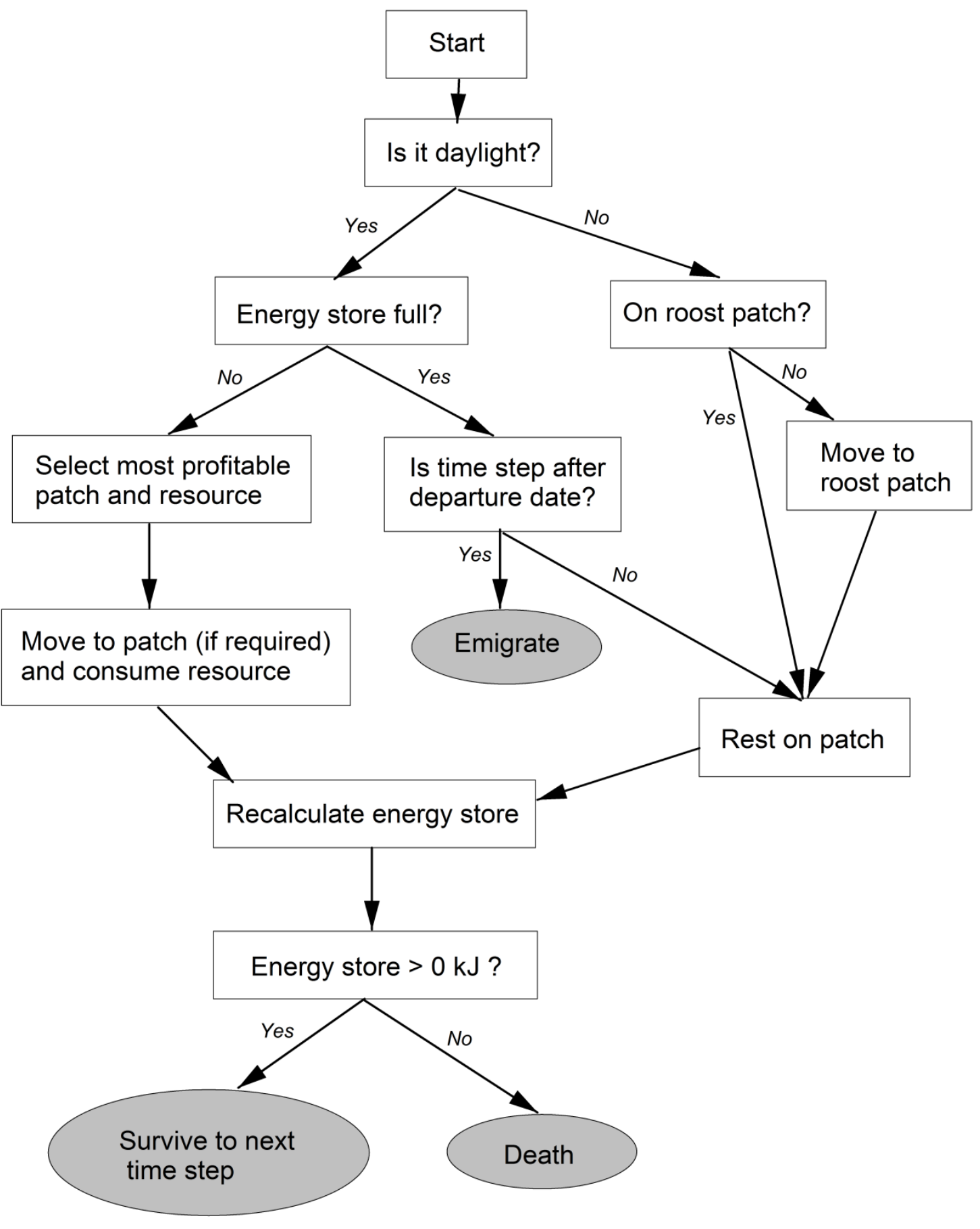

1068 Figure 2: A decision tree illustrating the decision-making process of each individual swan on 1069 each time step. 

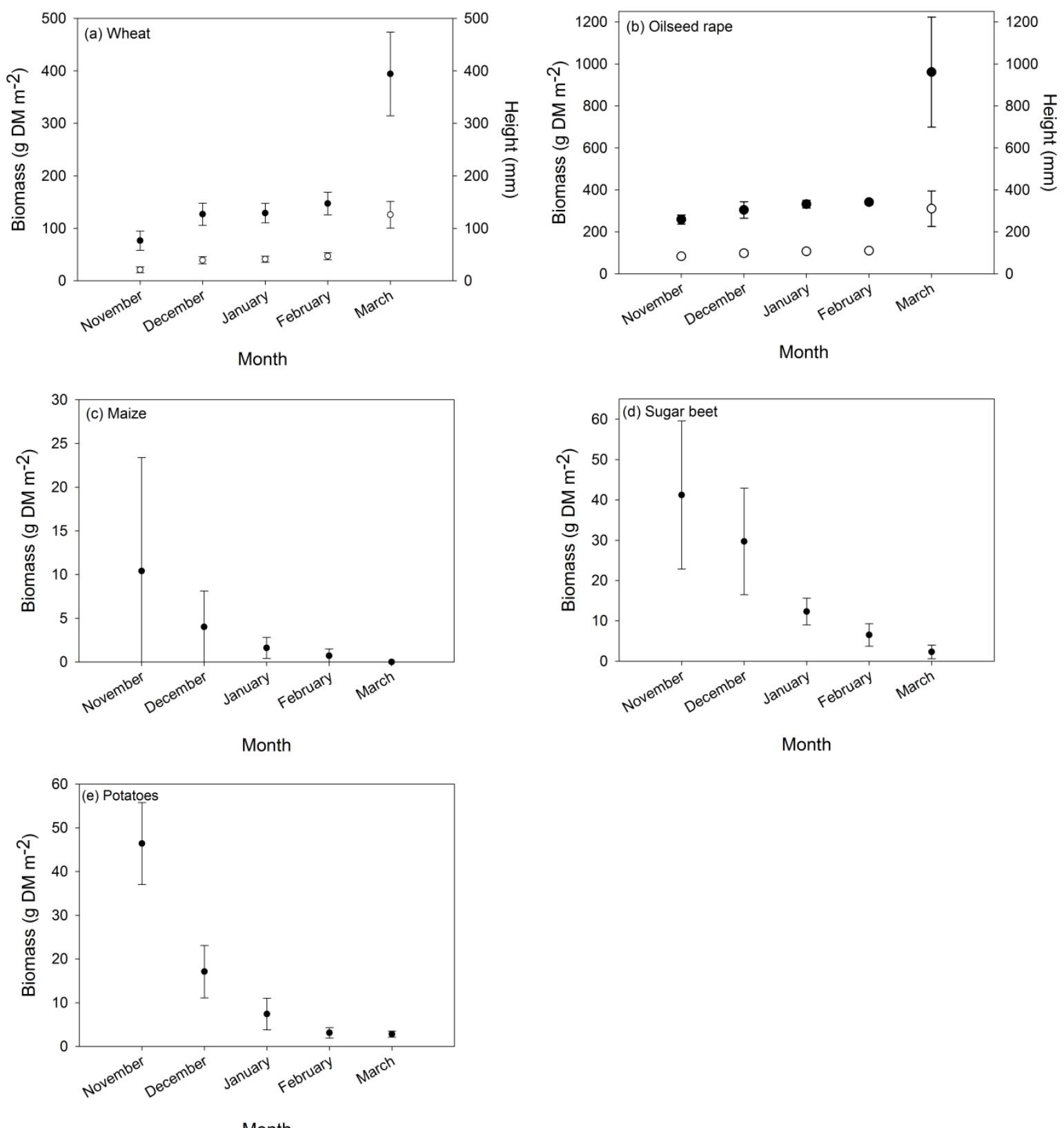

1071

Month

1072 Figure 3: Mean ( $\pm 95 \%$ CI) monthly dry matter biomass (black circles) of all crops in our

1073 study area, along with height (white circles) which was used in the calculation of biomass for 1074 wheat and oilseed rape. 

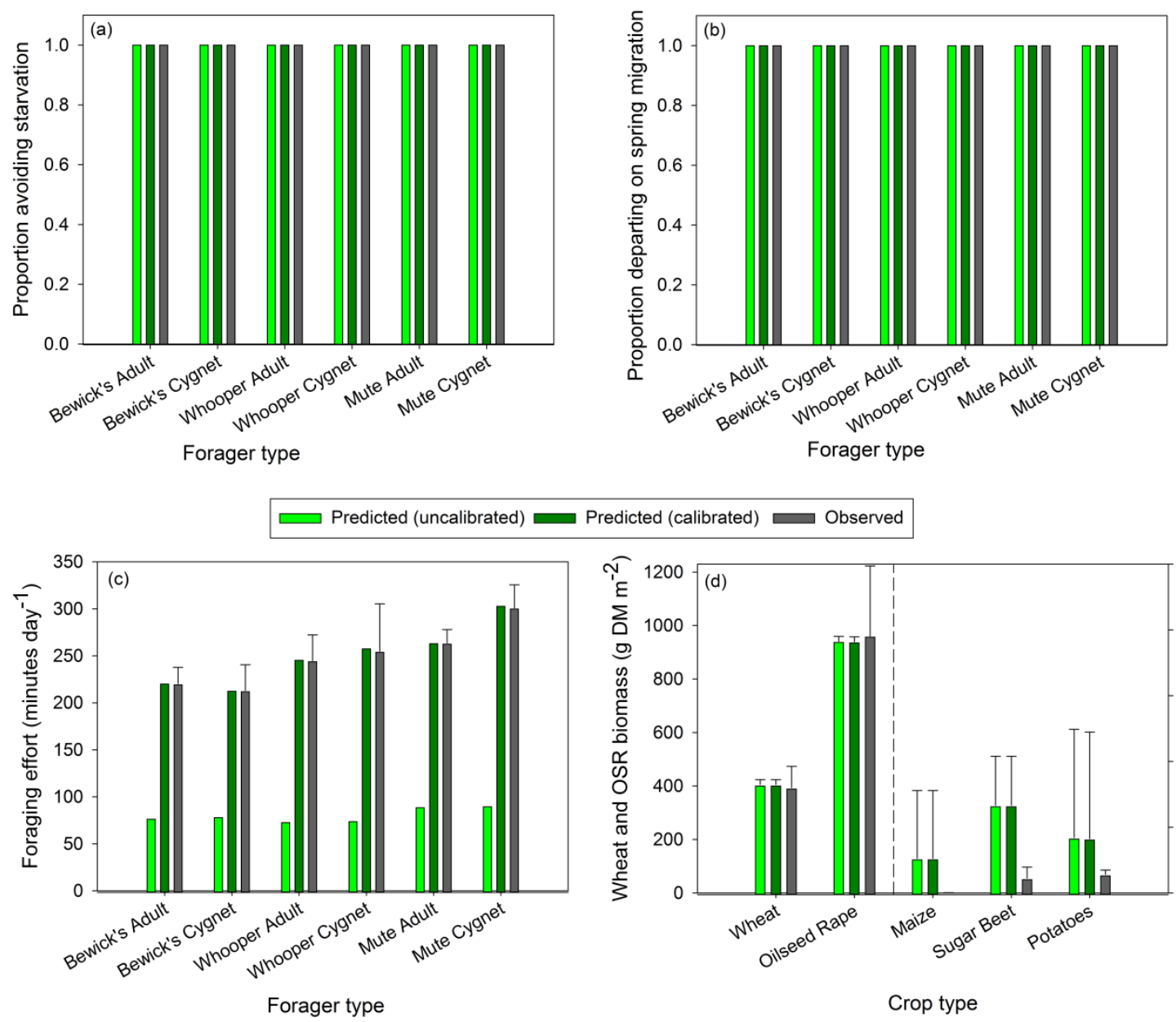

1076

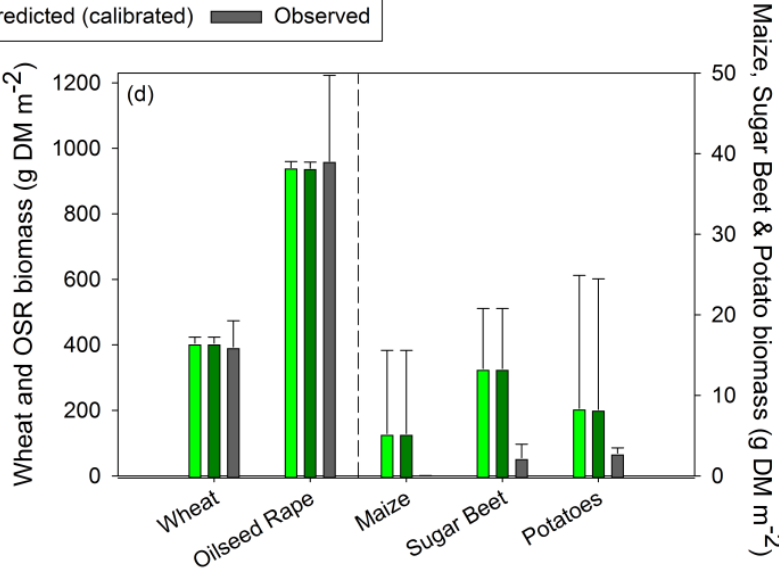

Crop type

1077 Figure 4: Comparisons of the baseline model predictions (both uncalibrated and calibrated

1078 versions) and observed values: (a) proportion of swans that avoided starvation, (b) proportion

1079 of swans that successfully departed at the end of winter, (c) mean ( $\pm 95 \% \mathrm{CI})$ number of

1080 minutes per day devoted to foraging, and (d) mean $( \pm 95 \% \mathrm{CI})$ crop biomass at the end of

1081 winter. 

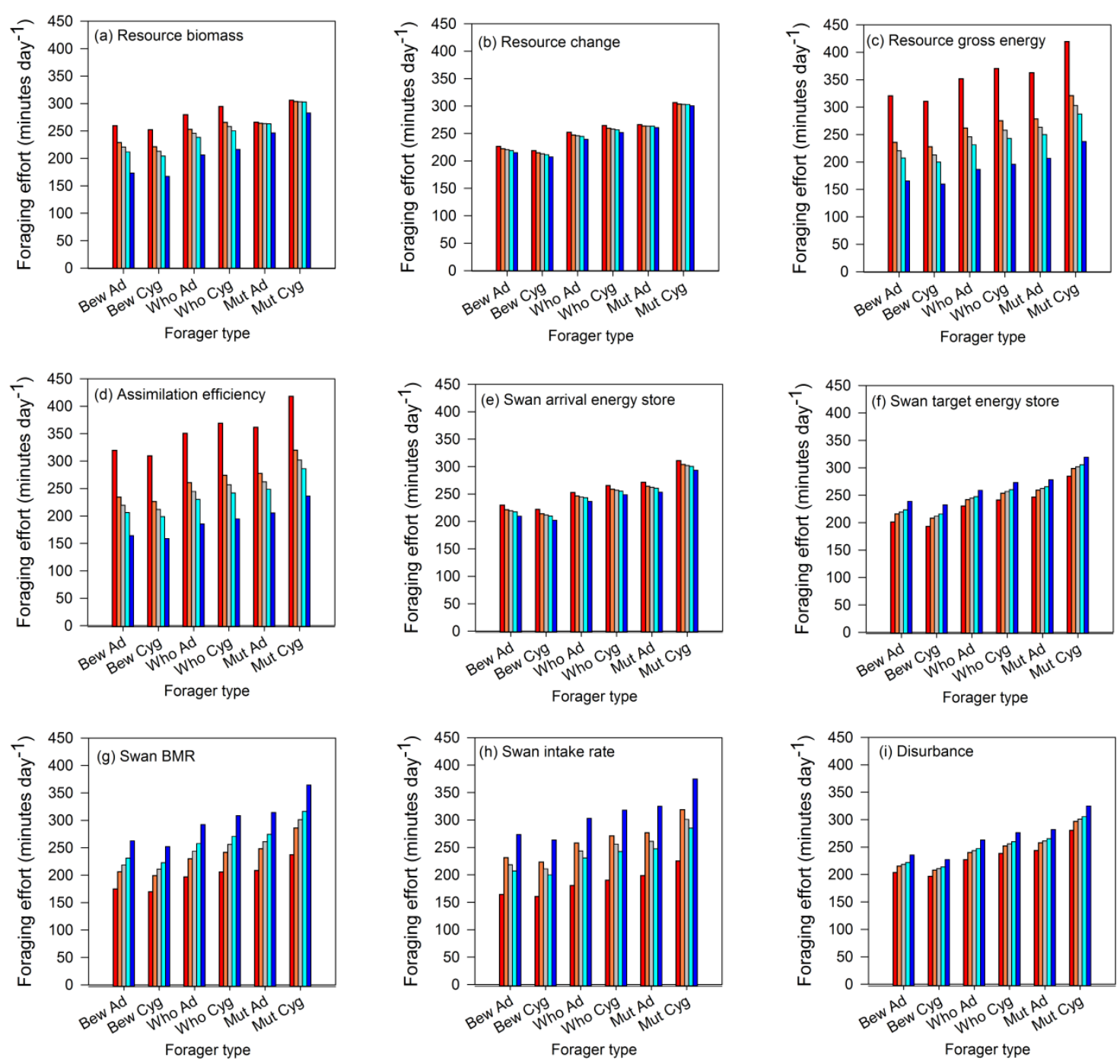

$-25 \% \square-5 \% \square$ Mean $\square+5 \%$

$+25 \%$

1085 Figure 5: Sensitivity of our calibrated model's predictions of daily foraging effort to

1086 variation in the values of nine major parameters. 
(a) Bewick's adults

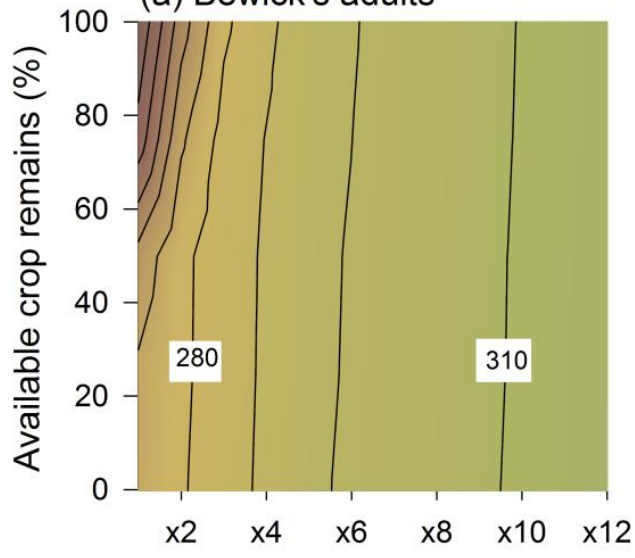

Relative no. swans

(c) Whooper adults

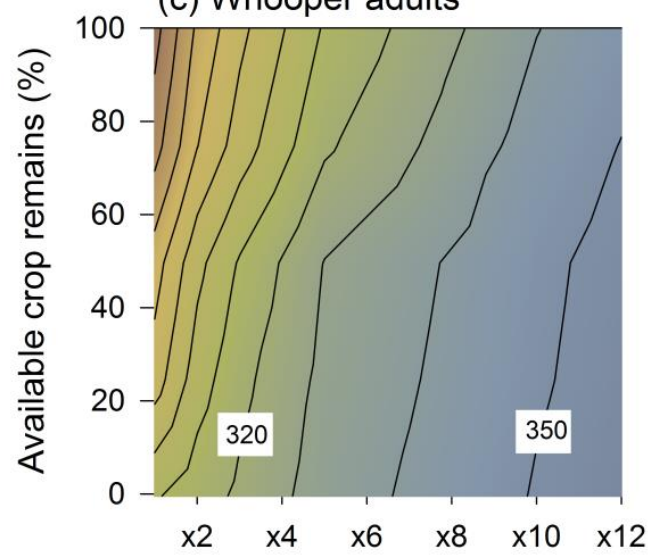

Relative no. swans

(e) Mute adults



(b) Bewick's cygnets



Relative no. swans

(d) Whooper cygnets


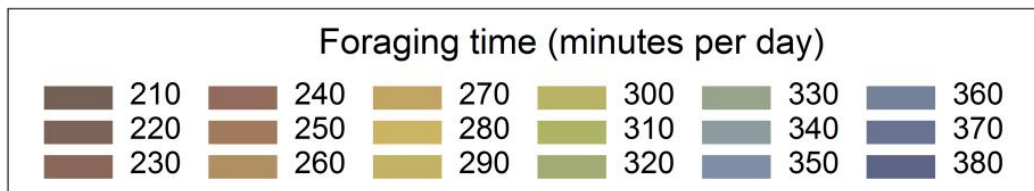


1089 Figure 6: Daily foraging effort of each forager type predicted by our calibrated model for 1090 different numbers of swans (relative to the $\mathrm{x} 1$ baseline simulation) and availability of post1091 harvest crop remains. Gaps between solid black lines indicate differences of 10 minutes of 1092 foraging time per day. Ranges of foraging times: (a) Bewick's swan adults 221.3-314.8 mins 1093 day $^{-1}$, (b) Bewick's swan cygnets 213.7-306.4 mins day ${ }^{-1}$, (c) whooper swan adults 246.41094355.2 mins day $^{-1}$, (d) whooper swan cygnets $258.7-377.3$ mins day $^{-1}$, (e) mute swan adults $1095 \quad 264.0-295.3$ mins day $^{-1}$, and (f) mute swan cygnets 303.7-340.5 mins day ${ }^{-1}$. 
(a) Wheat

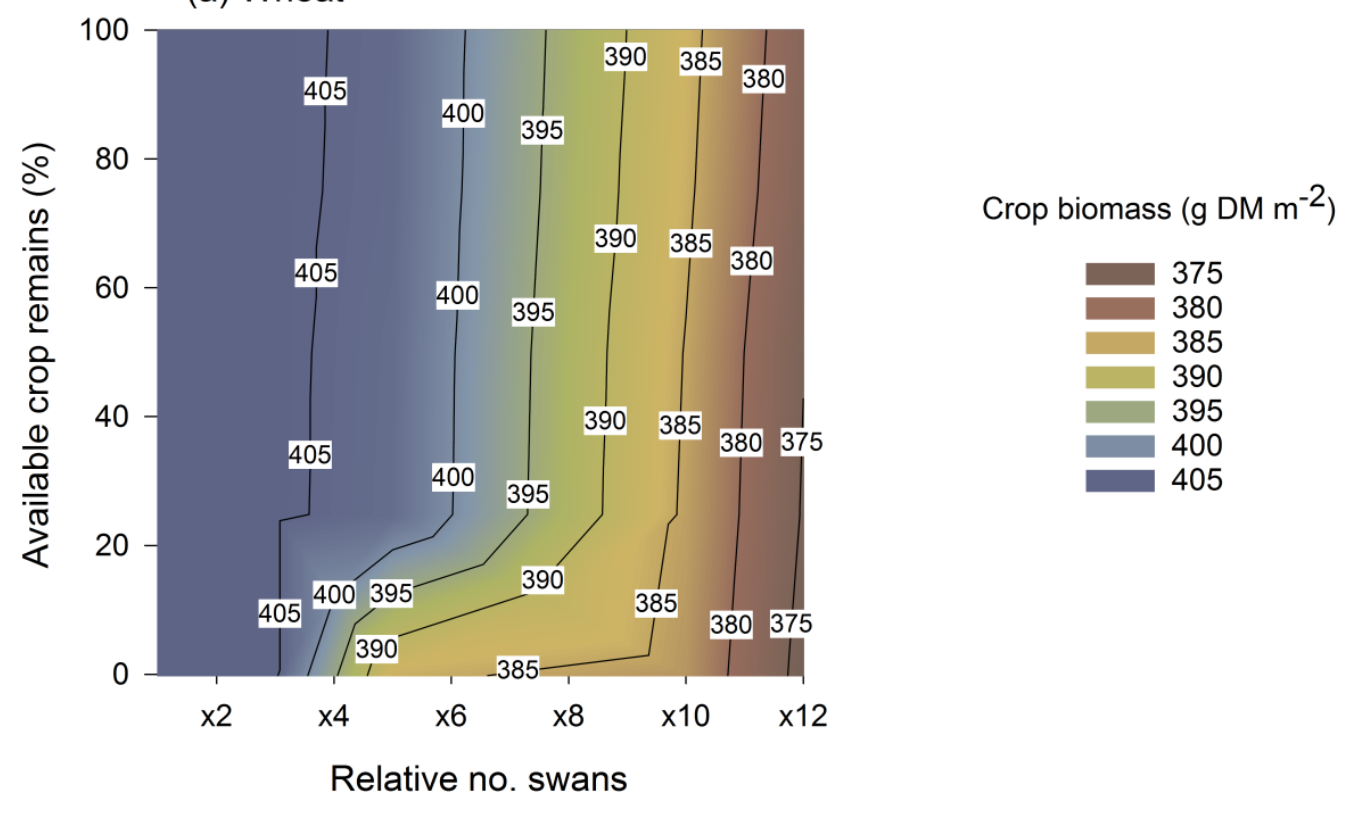

(b) Oilseed rape

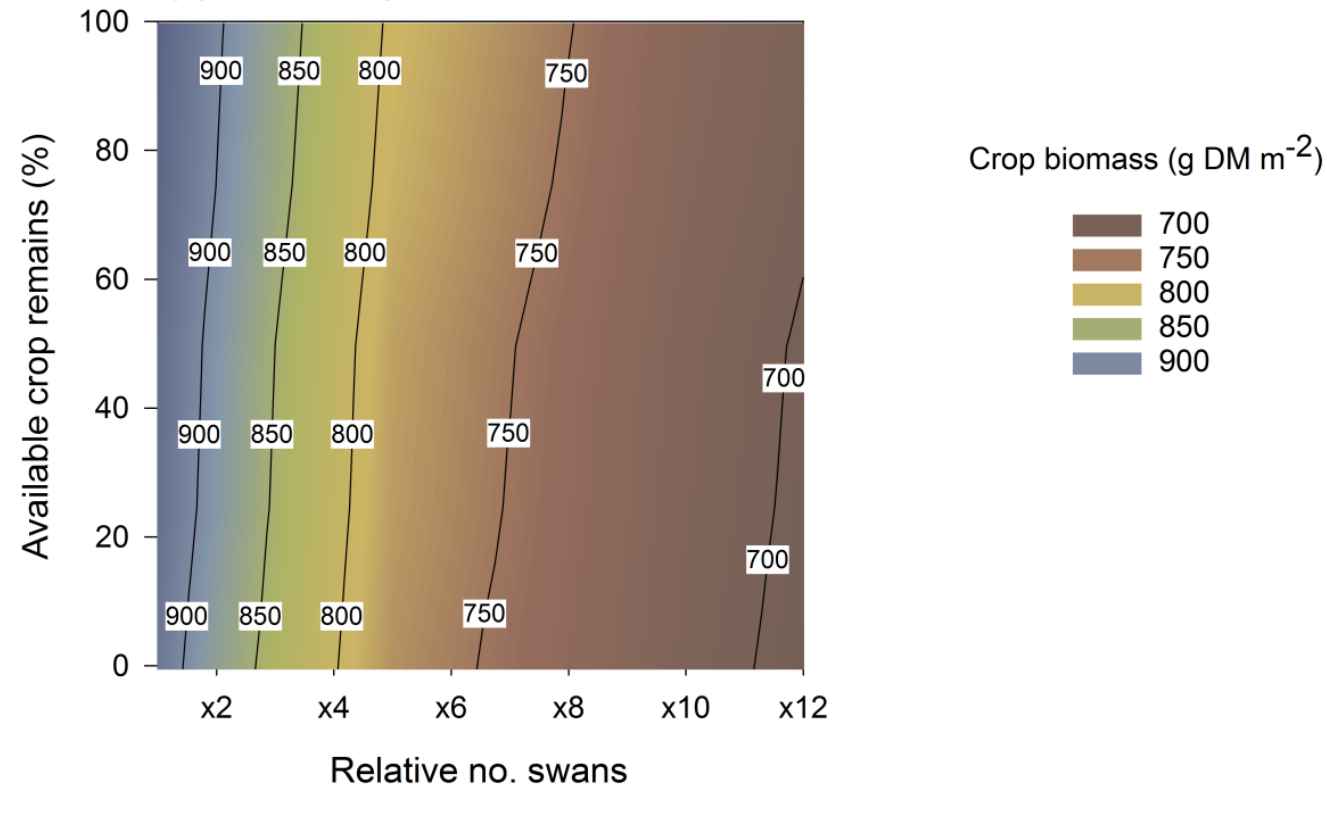

1098 Figure 7: Mean biomasses of (a) wheat and (b) oilseed rape in late winter (mid-March)

1099 predicted by our calibrated model in simulations with different numbers of swans (between

$1100 \mathrm{x} 1$ and $\mathrm{x} 12$ swan numbers in the base simulation) and varying post-harvest crop availability. 
Detailed experimental measurements of the Lower Critical Temperature (LCT), the threshold below which an organism must increase heat production to maintain body temperature, were not available for all three of our study species. Therefore, to allow consistent estimation of LCT for all swan species and age classes, we used an allometric equation (Calder and King 1974; Hughes and Green, 2005):

$T_{B}-\mathrm{LCT}=4.73 \cdot \operatorname{Mass}^{0.274}$

where $T_{B}$ was body temperature (measured as $39.7^{\circ} \mathrm{C}$ in winter-acclimatised mute swans; Bech, 1980) and Mass was the body mass of the swan in grams. The LCT values ranged from $-10.1^{\circ} \mathrm{C}$ for a $5,400 \mathrm{~g}$ Bewick's swan cygnet to $-20.6^{\circ} \mathrm{C}$ for a $10,800 \mathrm{~g}$ adult mute swan (Appendix Table A1), whereas the lowest air temperature recorded during our video observations was $-1.0^{\circ} \mathrm{C}$ (Appendix Figure A1). We therefore did not adjust energy expenditure to account for ambient temperature because the observed temperatures did not reach below the lowest LCT for our study animals.

Table A1: The body mass, basal metabolic rate, and lower critical temperature calculated for each forager type included in our model.

\begin{tabular}{llrrr}
\hline Species & Age class & Body mass $(\mathbf{g})$ & BMR $(\mathbf{W})$ & LCT $\left({ }^{\circ} \mathbf{C}\right)$ \\
\hline Bewick's swan & Adult & 6000 & 17.2 & -11.6 \\
& Cygnet & 5400 & 15.9 & -10.1 \\
\multirow{2}{*}{ Whooper swan } & Adult & 9700 & 24.6 & -18.8 \\
& Cygnet & 8700 & 22.5 & -17.1 \\
& Adult & 10800 & 26.4 & -20.6 \\
& Cygnet & 8800 & 23.1 & -17.3 \\
\hline
\end{tabular}




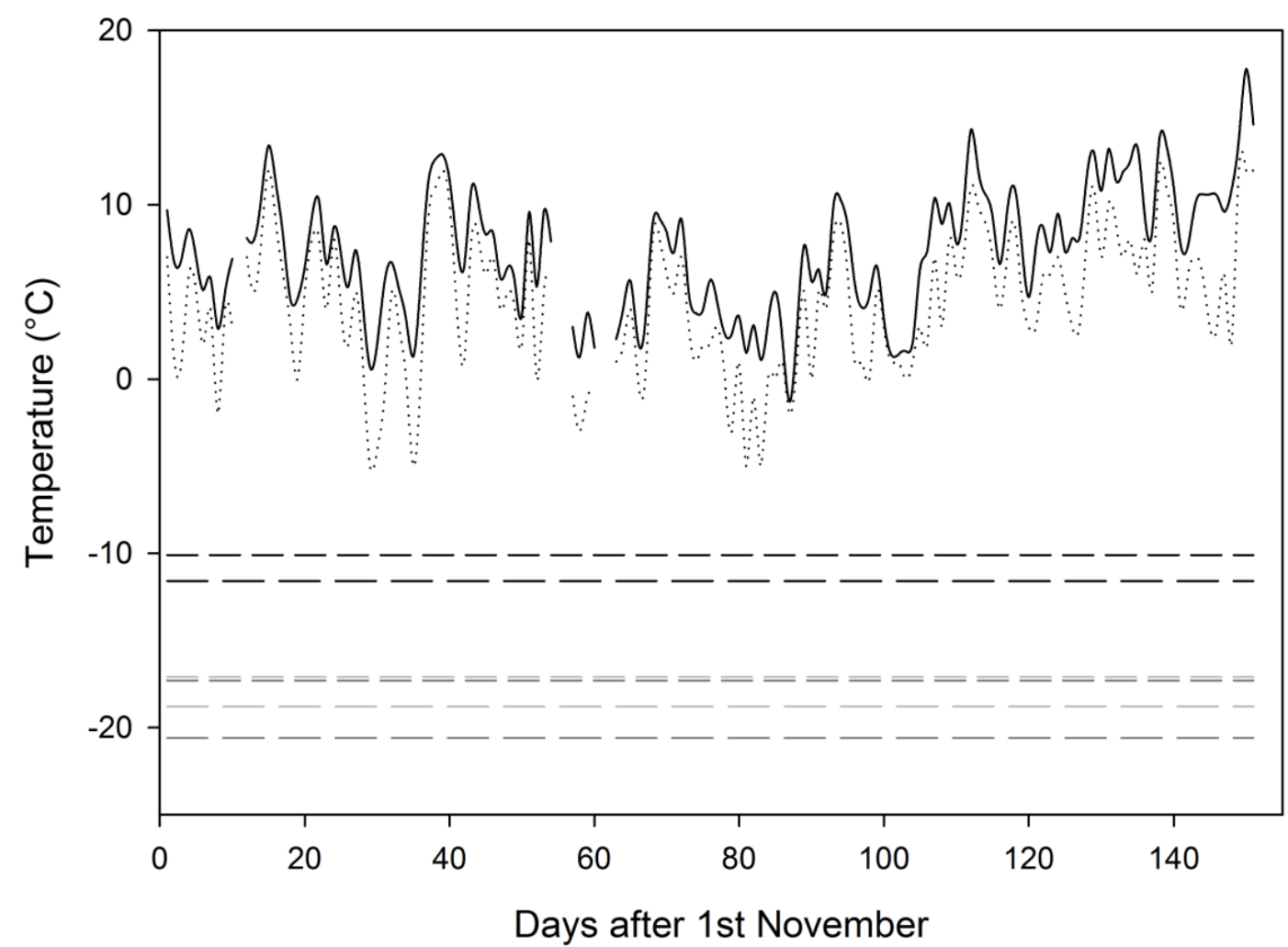

Days after 1st November

Mean daily temperature of study area Minimum daily temperature of study area

Adult Bewick's swan LCT

Cygnet Bewick's swan LCT

Adult whooper swan LCT

Cygnet whooper swan LCT

Adult mute swan LCT

Cygnet mute swan LCT

1122 Figure A1: The mean and minimum daily temperature values between $1^{\text {st }}$ November 2016

1123 and $31^{\text {st }}$ March 2017 for our study area compared with the LCT values for each of the forager

1124 types in our model. Temperature data were obtained from the TuTiempo website (TuTiempo,

1125 2019) for the nearest weather station, RAF Lakenheath, c.14km from our study site.

\section{References}


1128 Bech, C., 1980. Body temperature, metabolic rate, and insulation in winter and summer 1129 acclimatized mute swans (Cygnus olor). J. Comp. Physiol. B 136: 61-66.

1130 Calder, W.A., King, J.R. 1974. Thermal and caloric relations of birds, in: Farner, D.S., King, 1131 J.R., Parkes, K.C. (Eds.), Avian Biology Volume 4. Academic Press, pp. 259-413.

1132 Hughes, B., Green, A.J., 2005. Feeding ecology, in: Kear, J. (Ed.), Ducks, Geese and Swans. 1133 Oxford, UK, Oxford Univ. Press, pp. 27-56.

1134 TuTiempo., 2019. Tutiempo weather data. www.tutiempo.net. Last accessed August 2019. 
The patterns used to evaluate whether our model made sufficiently realistic predictions to meet its stated purpose were: (i) the proportion of the model swans that could be supported by the study area within the model, (ii) the proportion of swans that successfully emigrated in late winter, (iii) the total amount of time spent by swans on foraging behaviour each day, and (iv) the biomasses of each crop type in late winter. Data on each of these four patterns were available from fieldwork undertaken in the study area:

(i) Predicted proportions of swans that avoid starvation were evaluated against real-world swan mortality data. Details of the carcass searches and post-mortem analyses have been reported elsewhere (e.g. Brown et al., 1992; Newth et al., 2013; Wood et al., 2019a), and so here we limit ourselves to reporting only the most salient details. Post-mortem analyses were carried out on, and the cause of death determined for, a total of 180 swans, comprising 29 Bewick's (23 adults, 5 cygnets, 1 unknown age), 143 whooper (90 adults, 35 cygnets, 18 unknown age), and 8 mute (5 adults, 1 cygnets, 2 unknown age) swans, that were found dead between 1971 and 2019 in the vicinity of the Ouse Washes. Of these 180 swans subjected to post-mortem examinations, none was found to have died from starvation. The most common cause of death for all species was collision with power lines: 16 out of 29 Bewick's swans, 6 out of 8 mute swans, and 43 out of 143 whooper swans. Our data concord with the findings of an earlier study on the Ouse Washes by Owen and Cadbury (1975), which reported 128 dead swans between 1969 and 1975. Of these the cause of death was determined for 74 individuals (47 Bewick's, 3 whooper, 22 mute, and 2 unknown swans), of which none was found to have died of starvation. Furthermore, our findings accorded with other independent studies which have reported no cases of starvation among swans overwintering in the UK (e.g. Ogilvie, 1967; Hardman and Cooper, 1980; Birkhead, 1982; MacDonald et al., 1990). Therefore, we considered that accurate model predictions would indicate no incidences of starvation among 
model birds of any forager type. We acknowledge that as the true probability of starvation was 0.0 , the model could only deviate from this by overestimating the probability (i.e. the model could not underestimate starvation probability), which reduces the sensitivity of the test. However, we argue that our modelling approach was strengthened by having multiple tests, rather than reliance on a single test, as the use of multiple tests reduces the possibility that our model gave accurate predictions for the wrong reasons (Grimm and Railsback, 2012).

(ii) The proportion of swans that successfully departed from the study area at the end of winter, as predicted by the model, was compared with count data available for our study area (Owen and Cadbury, 1975; Wood et al., 2019c; WWT, unpublished). As detailed by Wood et al. (2019b) and Wood et al. (2019c), systematic surveys of swan numbers on the Ouse Washes have been carried out during winter months between the 1970s and the present. These surveys have shown that swans do not remain behind on the fields after the winter period, and hence we considered that accurate model predictions would indicate no incidences of individuals of any forager type that were unable to emigrate successfully after the winter period. As with starvation probability, we acknowledge that as the true probability of emigration was 1.0, the model could only deviate from this by underestimating the probability (i.e. the model could not overestimate emigration probability), which reduces the sensitivity of the test. However, we reiterate that our modelling approach was strengthened by the use of multiple tests, rather than reliance on a single test, as the use of multiple tests reduces the possibility that our model gave accurate predictions for the wrong reasons (Grimm and Railsback, 2012).

(iii) We compared the predictions of the number of minutes per day devoted to foraging with field data available from time-activity budgets carried out in our study area from 2015-2018 (Wood et al. 2019b). Details of the methodology of the time-activity budget study were 
reported by Wood et al. (2019b), and so here we limit ourselves to reporting only the most salient points. Foraging was defined the total time spent actively searching for and consuming food, but did not include any time spent on vigilance, travelling, or other behaviours (Wood et al. 2019b). Behavioural observations, using the focal observation method (Altmann, 1974), were carried out between winters 2015/16 and 2017/18 on 1,083 swans (mean \pm 95\% CI observation duration $=8.5 \pm 0.3$ minutes), comprising 300 adult Bewick's, 85 cygnet Bewick's, 106 adult mute, 23 cygnet mute, 444 adult whooper, and 125 cygnet whooper swans. Behavioural observations were carried out on swans using all five crop types: wheat ( $n=441$ observations), oilseed rape $(n=205)$, maize $(n=121)$, sugar beet $(n=246)$, and potatoes $(n=70)$. The time-activity budget study found that the mean $\pm 95 \%$ CI daily foraging effort for each forager type ranged from 213.1 \pm 27.4 minutes for Bewick’s swan cygnets to $301.0 \pm 24.5$ minutes for mute swan cygnets. We considered that accurate model predictions would be indicated by predicted time spent foraging that matched the values for each forager type that were obtained from the time-activity budget study. As the model could potentially under- or over-estimate foraging effort, this was considered a particularly sensitive test of the model predictions.

(iv) To allow us to evaluate the model's simulations of the resources, the predicted and observed mean biomasses of each crop type at the end of winter (i.e. mid-March, to coincide with the timing of field sampling) were compared. In the model, the crop biomass on each time step resulted from the initial crop biomass (as specified during model set up), the rates of change in biomass that were specified for each month, and the quantities consumed by the swans during the simulation. Our field sampling (see main text for details) indicated that the mean $\pm 95 \%$ CI crop biomass in mid-March were: wheat $=394.2 \pm 79.7 \mathrm{~g} \mathrm{DM} \mathrm{m}^{-2}$, oilseed rape $=961.1 \pm 261.8 \mathrm{~g} \mathrm{DM} \mathrm{m}^{-2}$, maize $=0.04 \pm 0.01 \mathrm{~g} \mathrm{DM} \mathrm{m}^{-2}$, sugar beet $=2.3 \pm 1.7 \mathrm{~g} \mathrm{DM}$ $\mathrm{m}^{-2}$, potatoes $=2.8 \pm 0.7 \mathrm{~g} \mathrm{DM} \mathrm{m}^{-2}$. We considered that accurate model predictions would be 
indicated by predicted late winter crop biomasses that matched the values for each crop type that were obtained from the our field sampling. As the model could potentially under- or over-estimate crop biomasses, this was considered a particularly sensitive test of the model predictions.

\section{References}

Altmann, J., 1974. Observational study of behavior: sampling methods. Behaviour 49, 227 266.

Birkhead, M., 1982. Causes of mortality in the mute swan Cygnus olor on the River Thames. J. Zool. 198, 15-25.

Brown, M.J., Linton, E., Rees, E.C., 1992. Causes of mortality among wild swans in Britain. Wildfowl 43, 70-79.

Grimm, V., Railsback, S.F., 2012. Pattern-oriented modelling: a 'multi-scope' for predictive systems ecology. Philos. Trans. Royal Soc. B 367, 298-310.

Hardman, J.A., Cooper, D.R., 1980. Mute Swans on the Warwickshire Avon - a study of a decline. Wildfowl 31, 29-36.

MacDonald, J.W., LiGoater, R., Atkinson, N.K., Small, J., 1990. Further causes of death in Scottish swans (Cygnus spp.). State Veterinary J. 44, 81-93.

Newth, J.L., Cromie, R.L., Brown, M.J., Delahay, R.J., Meharg, A.A., Deacon, C., et al., 2013. Poisoning from lead gunshot: still a threat to wild waterbirds in Britain. Eur. J. Wildlife Res. 59, 195-204. 
Ogilvie, M.A., 1967. Population changes and mortality of the Mute Swan in Britain.

1232 Wildfowl 18, 64-73.

1233 Owen, M., Cadbury, C.J., 1975. The ecology and mortality of swans at the Ouse Washes, 1234 England. Wildfowl 26, 31-42.

1235 Wood, K.A., Brown, M.J., Cromie, R.L., Hilton, G.M., Mackenzie, C., Newth, J.L., et al., 1236 2019a. Regulation of lead fishing weights results in mute swan population recovery. Biol. 1237 Conserv. 230, 67-74.

1238 Wood, K.A., Hilton, G.M., Newth, J.L., Rees, E.C., 2019b. Seasonal variation in energy gain 1239 explains patterns of resource use by avian herbivores in an agricultural landscape: Insights 1240 from a mechanistic model. Ecol. Model. 409, 108762.

1241 Wood, K.A., Newth, J.L., Brides, K., Burdekin, M., Harrison, A.L., Heaven, S., et al., 2019c. 1242 Are long-term trends in Bewick's Swan (Cygnus columbianus bewickii) numbers driven by 1243 changes in winter food resources? Bird Conserv. Int. 29, 479-496. 